\title{
Using Length, Age and Tagging Data in a Stock Assessment of a Length Selective Fishery for Gummy Shark (Mustelus antarcticus)
}

\author{
Fred Pribac and André E. Punt \\ CSIRO Marine Research, GPO Box 1538, Hobart, TAS 7001, Australia \\ Bruce L. Taylor, Terence I. Walker \\ Marine and Freshwater Research Institute, Primary Industries Research Victoria \\ P. O. Box 114, Queenscliff, VIC 3225, Australia
}

Pribac, F., A. E. Punt, B. L. Taylor, and T. I. Walker. 2005. Using Length, Age and Tagging Data in a Stock Assessment of a Length Selective Fishery for Gummy Shark (Mustelus antarcticus). J. Northw. Atl. Fish. Sci., 35: 267-290. doi:10.2960/J.v35.m521

\begin{abstract}
Gummy shark (Mustelus antarcticus Günther) populations in Bass Strait and off South Australia are assessed using a variant of the Integrated Analysis method of fisheries stock assessment. The assessment model is age- and sex-structured, takes account of gear selectivity and explicitly considers the peculiarities of the pupping process. Catch, catch-rate, length-frequency, age-composition and tagging data are used within a maximum-likelihood estimation framework to estimate the free parameters of the model. The current pup production is estimated to be in excess of conventional target and limit levels. The relationship between fishing effort and fishing mortality is estimated to saturate at high levels of fishing effort. The availability of gummy sharks to fishers is estimated to be non-uniform. The use of length- and age-composition data allow estimation of year-class strength and also the potential to provide support for more complicated model structures. In this case, the support for the hypothesis that availability is not the same for all gummy sharks rests on evidence in the length-frequency data. Whether any one data source may be providing misleading impressions regarding population trends can be examined only if the assessment includes several data sources. In the case of gummy shark in Bass Strait, estimates of productivity and natural mortality are sensitive to whether the tagging or length-frequency data are included in the assessment.
\end{abstract}

Key words: age, Australia, catch, gummy shark, length-frequency, stock assessment, tagging, yearclass

\section{Introduction}

The main target species of Australia's Southern Shark Fishery (SSF) are school shark (Galeorhinus galeus) and gummy shark (Mustelus antarcticus Günther). These species are taken predominantly by demersal gillnets and longlines although some are also taken as by-catch by other gears such as demersal trawl. Landings by the SSF have varied between 2234 and 4226 tons (carcass weight) during the period from 1970 to 2000 (Fig. 1). However, the species composition of these landings has changed markedly over the past 15 years. In 1987, gummy and school sharks constituted 40 and $46 \%$, respectively, of the total shark catch in the SSF, whereas, in 2000, these percentages were 69 and $11 \%$, respectively. Assessment of school shark stocks (e.g. Punt and Walker, 1998; Punt et al., 2000a) has been a focus for several years owing to the perception that the school shark resource is highly depleted. However, as gummy shark has become a more important economic component of the SSF catch there has been an increasing need for reliable information about the population dynamics and current status of gummy shark populations ${ }^{1}$.

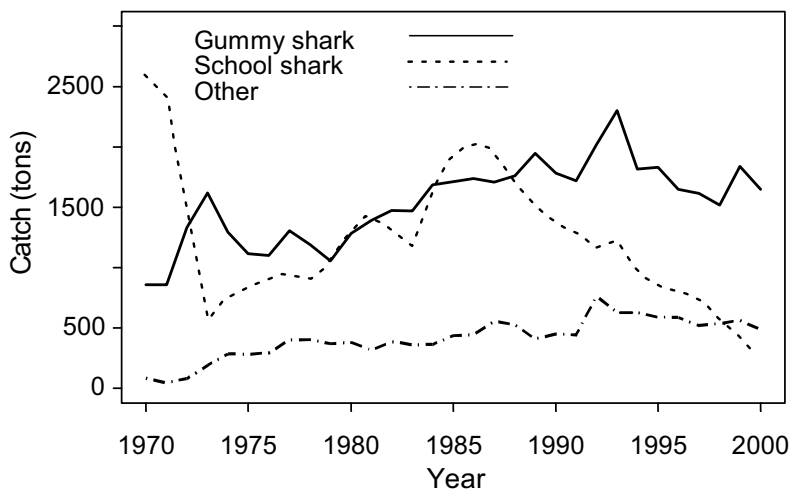

Fig. 1. Catches (1970-2000) of gummy and school shark (Source: Walker et al., 2001).

\footnotetext{
1 It is known that at least four species of Mustelus are found in the Australian region with at least three genetic stocks of Mustelus antarticus. However, only one genetic stock of M. antarticus has been found in the area of the SSF (McDonald, 1988; Ward and Gardner, 1997) and it is this stock that forms the focus for this paper.
} 
Quantitative assessments for gummy shark have been based on a wide variety of methods, ranging from yield-per-recruit approaches (Walker, 1986) to applications of age- and sex-structured production model approaches (Prince, MS 1992; Walker, 1992, 1994a, 1994b, 1998). Until the present assessment, the age-structured assessments assumed that the natural mortality rate was density-dependent, ignored inter-annual fluctuations in pup survival and used only a sub-set of the available information (catch rates and information on the mean weight or length of the catch) to estimate the parameters of the model. The full information content of the available data which includes age-composition and tagging information was not being used.

This paper therefore develops the first assessment approach for a shark population that is capable of utilizing all of the available information within the 'Integrated Analysis' approach to fisheries stock assessment. It also includes key aspects of shark population biology such as the (relatively) low number of pups per mature female and the wide variety of gear-types employed in the fishery. The 'Integrated Analysis' approach is being used increasingly in assessments of fish stocks off Australia (e.g. Smith and Punt, 1998; Punt et al., 2001a; Smith et al., 2001) and elsewhere. In contrast, this approach is not being used to conduct assessments of shark populations worldwide, owing primarily to lack of information on the length- and age-composition of the catches. Previous assessments of gummy shark off southern Australia have focused on estimating the size of the population prior to fishing and the parameters that determine the productivity of the resource. However, using the additional data, it becomes possible to estimate additional model parameters, in particular the sizes of annual recruitments.

Gummy sharks within the SSF are assessed as three separate stocks corresponding to the three broad regions of South Australia, Bass Strait and Tasmania (Fig. 2). These three regions were chosen principally for pragmatic reasons associated with management jurisdiction boundaries, regional differences in targeting practices over time and differences in the types, amount and quality of data available (the data set for Bass Strait is extensive whereas the data for Tasmania are sparse). However, there are also differences in habitat between these regions, differences in the proportion of gummy shark breeding in Bass Strait and South Australia (Walker et al., MS 1989), and a much smaller population off Tasmania. Gummy shark movement among these regions is low (Walker et al., MS

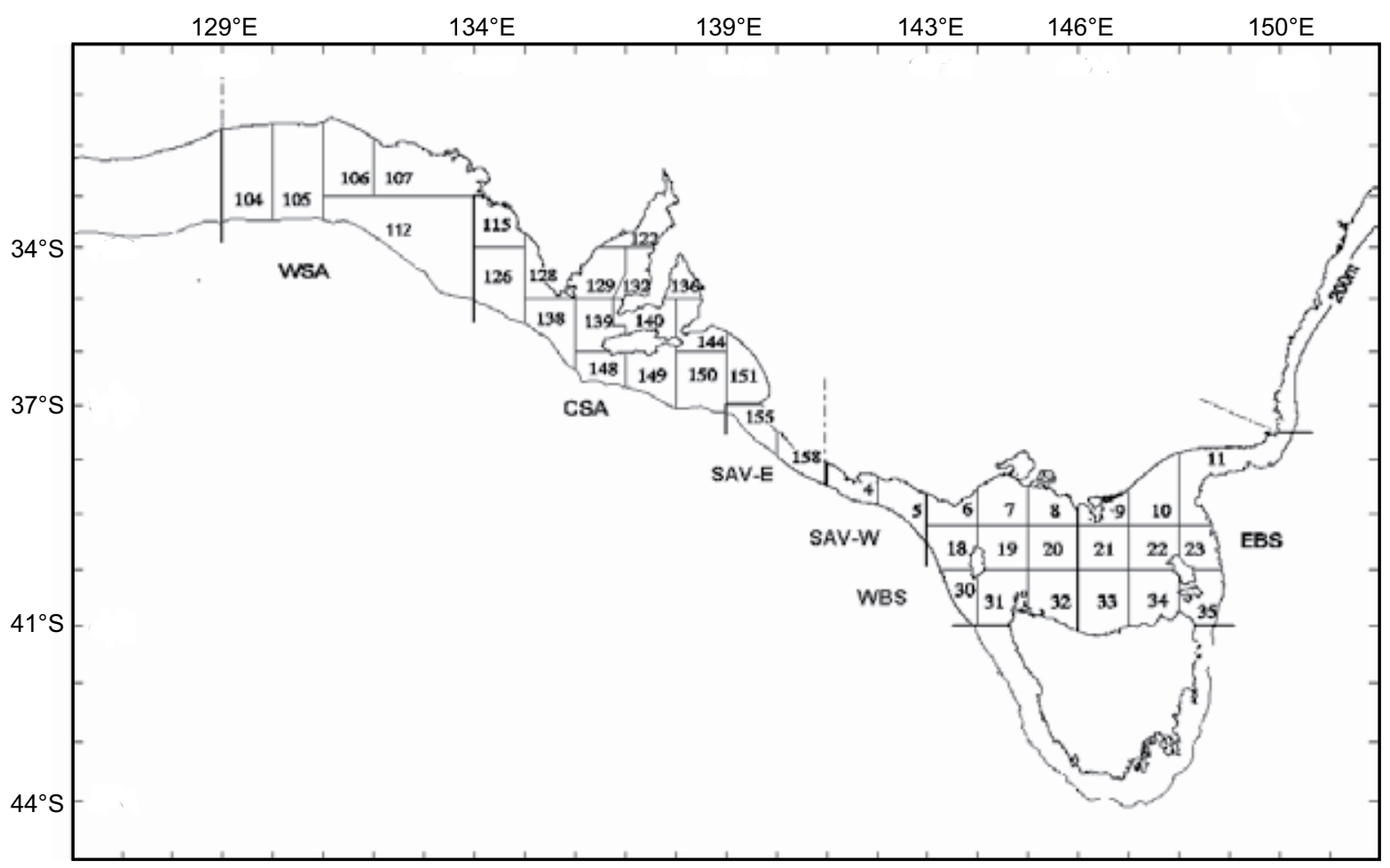

Fig. 2. Map of southern Australia showing the sub-regions and 42 statistical cells used when standardizing the catch and effort data. The South Australian region consists of sub-regions WSA, CSA, and SAV-E and the Bass Strait region consists of sub-regions SAV-W, WBS, and EBS. The Tasmanian region is south of latitude $41^{\circ} \mathrm{S}$. 
2000). The analyses of this paper focus solely on Bass Strait and South Australia owing to a lack of data for the (small) population off Tasmania.

\section{Materials and Methods}

\section{Data utilized}

The data available for assessment purposes include catches by gear-type (1927-98), catch-rates (1976-98), length-frequency data (1970-98), age-composition data (1986-87, 1990-93) and tagging data (1943-98). Each of these data sources is described in turn below.

Catch data. Previous assessments of gummy shark have been based on catch data for the gill-net and longline sectors only. In contrast, the analyses of this paper are based on catch data for the gill-net (6-inch, 6.5-inch, 7inch and 8-inch mesh sizes), longline, and trawl sectors (Australia's South East Trawl and Great Australian Bight Trawl fisheries). However, there are at least three reasons why the recorded historical catches of gummy shark may be in error; deliberate mis-reporting during 1973-85 when a ban was imposed on landing large school shark in Victoria due to concerns regarding mercury content, general under-reporting and reporting of 'paper fish' in anticipation of possible management actions. Therefore, in addition to a catch series based on the 'best estimates'of the historical catches, analyses are also conducted for an alternative series of historical catches. This series involves increasing the catches (all regions) by 15\% (1927-79), $10 \%(1980-89)$ and $5 \%(1990-96)$ to reflect the first two sources of error.

Catch-rate indices. Detailed information from logbooks on catch and effort has been collected since 1973 . However, the level of detail recorded and coverage across the fishery has changed over time. Standardized catch rate series for gummy shark have been derived separately for South Australia and Bass Strait using an approach developed for school shark (Punt et al., MS 2000b). This involved developing a set of criteria to identify those commercial fisheries operators whose catch and effort data should provide useful information about trends in the abundance of gummy shark. For example, the catchrates for operators who catch shark during periods when rock lobsters are unavailable to them, or incidentally take school or gummy shark as part of other targeted fishing operations are unlikely to provide reliable information about changes in abundance over time. These criteria involved selecting vessels that met minimum time periods in the fishery, used 6-inch, 6.5-inch or 7-inch mesh gillnets, and had minimum median annual catches (gummy shark and total shark catch). These criteria reduced the total number of vessels that could be potentially considered in the development of catch-rate series from over 2700 to only 61 (Punt et al., MS 2001b). These 61 vessels corresponded to $43 \%$ of the total catch of gummy shark over 1976-98 in Bass Strait and 29\% of the total gummy shark catch over 1984-98 off South Australia. The catch rate standardization for South Australia only starts in 1984 because reliable effort data are not available for this region prior to 1984 .

The data for the 61 selected vessels were standardized using a delta-lognormal approach (Punt et al., MS 2000b). The questions of whether a catch rate is zero or not, and the size of a non-zero catch rate were therefore treated separately. The non-zero catch rates were modeled using a negative binomial error model and whether the catch rate is zero or not was modeled as a Bernoulli random variable. The factors considered when modeling whether the catch is zero were year, statistical cell, vessel and month. Catch and effort data are reported for 56 statistical cells around southern Australia, aggregated into 42 statistical cells for purposes of the catch-effort standardization exercise, by pooling data for cells for which data are sparse or in which little fishing occurs (see Fig. 2). The factors considered when modeling the non-zero catch rates were year, statistical cell, vessel, month and the interaction between year and statistical cell. Other factors (e.g. depth) were examined, but found not to be significant. The results from fitting these models were used to compute time-series of standardized catch rate for each statistical cell and these were combined by weighting them by a proxy for the gummy shark 'habitat area' of each statistical cell (the area of each cell between 20 and $80 \mathrm{~m}$ ) to obtain a single catch-rate time-series for Bass Strait and South Australia. There are some combinations of year and statistical cell for which no data are available. Rules were therefore used to interpolate missing values (see Punt et al. MS 2001b for details). However, the results are not sensitive to the details of these rules because data were available for over $90 \%$ of the year-statistical cell combinations.

Tagging data. Sharks were tagged and released in the SSF during 1942-56, 1973-76 and 1987-99². Table 1 provides a summary of the tag data and tag types on which the assessments of this paper are based. Additional tagging data are available but cannot be used in the present assessments owing to lack of information on which to base estimates of tag-shedding rates, using the method of Xiao et al. (1999).

2 The tagging data for 1999 are commented on in this section but not included in the assessments, the terminal year for which is 1998. 
TABLE 1. The tag-types considered in the assessments of this paper. An asterisk indicates a tag-type for which the tag-shedding rate is assumed to be 0 .

\begin{tabular}{lclrr}
\hline \hline Tag-type & Years & \multicolumn{1}{c}{ Details } & \multicolumn{2}{c}{ Released Recovered } \\
\hline Nesbit (S-tag)* & $1942-56$ & Internal 3/4 35 mm long, 10 mm wide & 98 & 5 \\
Nesbit (L-tag)* & $1942-56$ & Internal 3/4 50 mm long, 22 mm wide & 488 & 52 \\
Roto & $1987-96$ & External 3/4 36 mm long, 9 mm wide & 2750 & 682 \\
Jumbo & $1993-96$ & External 3/4 45 mm long, 18 mm wide & 1870 & 680 \\
Dart - muscle & $1991-96$ & External 3/4 95 mm long, 2 mm diameter & 2265 & 401 \\
Dart - fin & $1991-96$ & External 3/4 95 mm long, 2 mm diameter & 691 & 120 \\
Nesbit (MAFRI)* & $1973-76$ & Internal - white (equivalent to S-tag) & 89 & 7 \\
Nesbit (MAFRI)* & $1973-76$ & Internal - yellow (equivalent to J/L tags) & 1436 & 373 \\
\hline
\end{tabular}

Length-frequency and age-composition data. Length-frequency and sex composition data for commercial gummy shark landings have been collected routinely by a team of fish measurers operating in several fishing ports and regional fish processing plants in Victoria. The data for Bass Strait during 1970-98 and South Australia during 1973-76 and 1986-98 are included in the present analyses. Total length was measured for each shark sampled at sea and the partial length from the fifth gill-slit to the base of the tail was measured for each shark sampled from commercial landings.

The sample sizes for longlines and 8-inch gill-nets are small (generally less than 100 fish per annum). Therefore, the assessment is based solely on the data for 6 -inch and 7-inch mesh (Bass Strait) and 6.5-inch and 7-inch mesh (South Australia). Length-frequency data are available for each sub-region separately (Fig. 2). Therefore to construct length-frequencies by region, the data by sub-region were combined after weighting by the corresponding catch. For Bass Strait, the 6-in mesh length-frequency data for 1984, 1985, and the years prior to 1974 and the 7-inch mesh length-frequency data for the years after 1974 are not included in the assessment. This is because the length-frequency data for 1984 and 1985 are known to be unreliable and the sample sizes for the other years are small.

Age-estimates have been made for gummy sharks sampled from Bass Strait (1973-75, 1986-87, and 199093), and South Australia (1986-87 and 1990-93) using the procedure of Moulton et al. (1992). The highest age estimates for gummy shark are 16 years for a female and 15 years for a male (Walker et al., 2001). The sample sizes for 1973-75 are very small and the data for these years are consequently not included in the assessment.

\section{The population dynamics model}

The basic population biology of gummy shark and the selectivity of the gear used in the SSF is reasonably well understood. Population dynamics models, based on that used by Punt and Walker (1998) to assess the school shark resource off southern Australia were developed for gummy shark (see Appendix A). These models include the nature of the pupping process, the selectivity patterns of the various gears used in the fishery, and the growth rates of gummy shark (Equations A.11 to A.13). Pup production is assumed to be related closely to the number of pregnant females (Equations A.3 and A.4) although allowance is also made for (limited) variability in pregnancy rates/pup survival rates so that the actual number of pups differs from the value predicted from the deterministic component of Equation (A.3). The magnitude of process error is determined by the value assumed for $\sigma_{r}$ (see Equation A.3). The choice for $\sigma_{r}$ of 0.4 is largely arbitrary and was chosen to be lower than the values for this parameter typically assumed for teleost fish (e.g. Beddington and Cooke, 1983) but greater than that assumed for school shark by Punt and Walker (1998).

Density-dependence is assumed to act through an impact on the natural mortality rate of a range of ageclasses (e.g. all ages, ages 0-4 and pups). Consistent with previous assessments of gummy shark (e.g. Walker, 1994a, 1994b), the model allows for density-dependent natural mortality. The base-case assumption is that density-dependence affects all age-classes (i.e $a_{d}$ in Equation (A.21) is equal to the maximum age, $x$ ) although sensitivity is examined to alternative assumptions including that density-dependence only impacts the survival rate of the pups $^{3}$ (see Equation A.3).

The population dynamics model includes both lengthspecific gear-selectivity (Equations A.14 and A.15 for longlines and gill-nets respectively) and length-specific availability (Equations A.16 and A.17). The values for the parameters of the selectivity functions are based on experimental results (Kirkwood and Walker, 1986). Differentiating availability from selectivity allows animals

3 This is essentially identical to assuming that density-dependence impacts the pregnancy rate. 
to be vulnerable to the gear (i.e. the selectivity of the gear allows them to be captured) but not to be available to the fishery (e.g. because they are not where the fishery operates) and hence not to be caught. Empirical evidence for non-uniform availability arises from analyses of lengthfrequency data collected during fishery-independent surveys (A. E. Punt, unpubl. data). Non-uniform availability may be a consequence of behavioral changes associated with ontogenetic changes in prey preference.

\section{Parameter and variance estimation}

The values for all of the parameters of the population dynamics model, except those related to the virgin biomass, $B_{0}$, the magnitude of density-dependence (determined through $M S Y R$ - the ratio of $M S Y$ to the biomass which $M S Y$ is achieved when exploitation is based on uniform selectivity harvesting of mature component of the population), the extent of variation in length-at-age (see Equation A.13), natural mortality $\left(M_{2}\right)$, the parameters that determine the relationship between effort and fishing mortality $\left(q, \gamma\right.$ and $\gamma_{1}-$ see Equations B.1 and B.2) and the recruitment residuals ( $\varepsilon_{t}-$ see Equation A.3) are fixed using ancillary information (see, for example, Table A.1). The values for the parameters not determined by ancillary information are estimated by maximizing a likelihood function that includes contributions from the catch-rate, length-frequency, age-composition and tagging data (see Appendix B). The estimates for the parameters $M_{2}$ and $M S Y R$ are constrained to lie within the intervals [0.1, $\left.0.3 \mathrm{yr}^{-1}\right]$ and $[0.1,0.3]$, respectively.

The approach used to include the catch-rate data in the likelihood function (Equations B.1-B.3) allows for a general relationship between fishing mortality and effort; Equation (B.2a) reflects the assumption that effort is linearly proportional to exploitation rate whereas Equations (B.2b) and (B.2c) allow for 'gear competition' effects. 'Gear competition' has been postulated for the fishery for gummy shark off southern Australia based on the observation that catches have been relatively insensitive to large changes in fishing effort. The forms chosen for Equations B.2b and B.2c are such that if the data support the concept of 'gear competition', this can be tested by means of a likelihood ratio test (Equation B.2a is nested within Equations B.2b and B.2c).

The variances for the estimates of the model parameters and for the other quantities of interest are determined using an 'asymptotic approach'. This involves finding the asymptotic variances for the parameters by inverting a numerical approximation to the Hessian matrix, generating 500 sets of parameter estimates from the estimated variance-covariance matrix and calculating the values for each interest quantity for each of the 500 sets. This approach is referred to as the 'numerical delta' method by Patterson et al. (2001).

\section{The scenarios considered}

Different modeling approaches have been adopted for Bass Strait (for which the data are most complete) and for South Australia. The Bass Strait assessment made use of tagging, catch-rate, age-composition, and length-frequency data to estimate the virgin biomass (the biomass at the start of 1927, the first year for which the catch data are available), productivity, availability, the rate of (adult) natural mortality, and the relative strength of each year-class. The estimates of availability, mortality and productivity for Bass Strait were then used to specify the values for these quantities for the South Australian assessment which used the available data to estimate the virgin biomass and the sizes of the various year-classes.

In order to constrain the volume of results, a base-case set of specifications was selected (these are considered by the assessment group to be the most plausible) and sensitivity tests conducted by varying the specifications of the base-case assessment. The base-case assessment uses all of the available information, estimates availability as a function of length, assumes that density-dependence impacts natural mortality (and not pup survival), and assumes that the relationship between fishing effort and fishing mortality is governed by Equation (B.2c).

\section{Results and Discussion}

\section{Analyses of the input data}

The time-trajectory of standardized catch rate for Bass Strait (Fig. 3b) declines slowly between 1976 and 1987, recovers to above the 1976 level in 1993 and declines sharply after 1995. In contrast, the standardized catch rate series for South Australia (Fig. 3a) is relatively stable, with a drop in catch rate in the final years. Sensitivity was explored to varying the specifications of the catch-rate standardization (e.g. by modeling the non-zero catches by means of log-gamma or Poisson error models and defining the 'habitat area' to be the area shallower than $200 \mathrm{~m}$ - Fig. 3). However, the results were found not to be particularly sensitive to changing any of these specifications.

Rototags and jumbo tags attached to the anterior lower portion of the first dorsal fin of sharks during 1987-99 were highly successful with low shedding rates $(0.139$ per year; SD 0.031). Similarly, internal tags inserted into the coelomic cavity of sharks during 1942-56 and 1973-76 were successful in that they were not shed. However, 

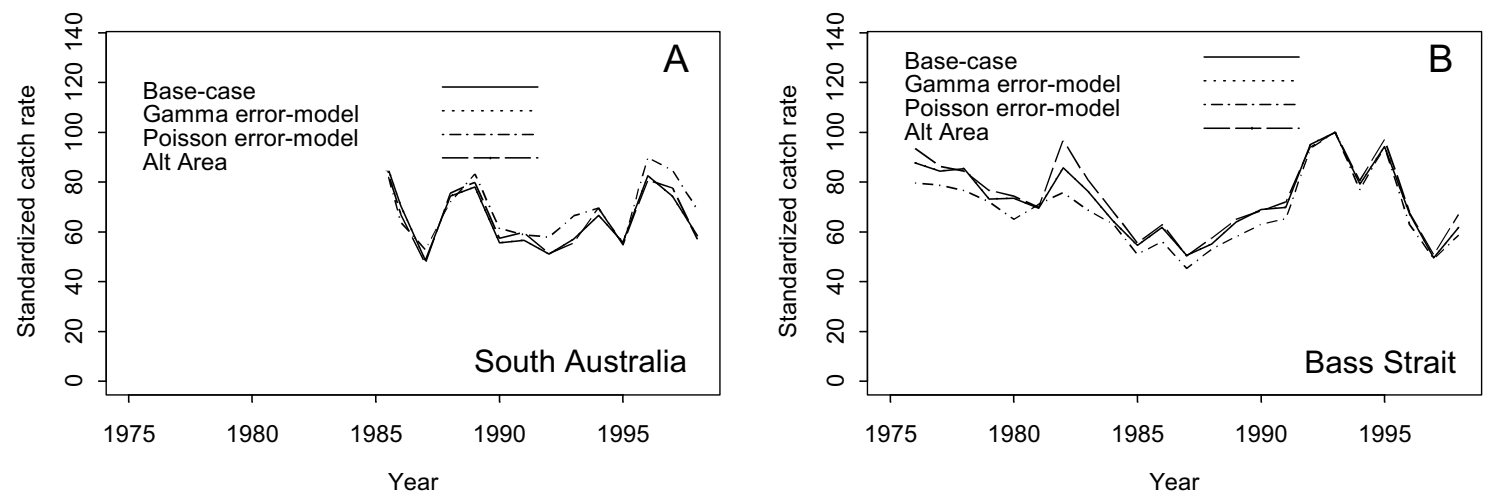

Fig. 3. The base-case catch-rate series and the sensitivity of these series to changing the definition of 'available' habitat ("Alt area") and changing the error model assumed when fitting to the data on non-zero catch rates ("Gamma error-model" and "Poisson error-model").

they were not always seen by fishers when the sharks were caught. Peterson disc fin tags attached to the first dorsal fins during 1947-56 and nylon-headed dart tags inserted into dorsal muscle tissue had very high shedding rates $(0.823$ per yeaer; SD 0.084). Inserting nylon-headed dart tags into the cartilage at the base of the first dorsal fin during 1990-99 rather than in the dorsal musculature reduced the shedding rate to a level that is not significantly different from that for roto- and jumbo tags. Brown and Walker (1999) estimated tag-reporting rates for South Australia and Bass Strait.

\section{Fits to data (base-case analysis)}

The ability of the model to mimic the catch-rate data (Fig. 3) is assessed by means of the observed and model-predicted exploitation rate time-series, i.e $F_{t, j} \times$ versus $f(E)$ - see Equation B.1. The model estimates that there is severe 'gear competition' in Bass Strait so that essentially the same expected exploitation rate results for all levels of standardized fishing effort during 1976-98 (Fig. 4). Gear competition is estimated to be substantial primarily because the effort data are negatively correlated with the estimated exploitation rates for some years. For example, the higher exploitation rates since 1990 and the lower exploitation rates during 1983-91 (dotted lines in Fig. 4) correspond to periods when effort was low and high respectively. In contrast to the situation for Bass Strait, the parameter, $\gamma_{1}$, that determines the extent of 'gear competition' is close to zero for South Australia and the model is able to track the observed exploitation rate trajectory remarkably closely (Fig. 4; right panel). The lack of 'gear competition' in South Australia is perhaps not unexpected because, although the absolute level of fishing effort in Bass Strait and off South Australia are similar, the fished area is much larger off South Australia than in Bass Strait.

The model is able to mimic the overall patterns in the length-frequency and the age-composition data for Bass Strait (see Fig. 5 and 6 for the fits to the length-frequency and age-composition data for 6 inch mesh gear). As expected, the fits to the data for the years for which sample size is large (and which hence get greater weight through the equation $W=N_{j}^{l e n} N_{g, t . j}^{l e n} / \bar{N}_{g, j}^{l e n}$ (see Equation B.4) tend to be better than to the data for those years for which the sample size is low. However, there is a tendency to overestimate the mean length of the catch, particularly for 7-inch mesh (not shown here). The fits to the age-composition data, although generally adequate (Fig. 6), are less than ideal for some years (1990 and 1991 for females and 1986 for males). The fits to the length-frequency and age-composition data are, however, notably poorer for South Australia than is the case for Bass Strait. There are even some cases in which the model fails to capture even the predominant lengths in the catch (e.g. 1997 for 6.5inch mesh; 1990 for 7-inch mesh). The reasons for this are unclear but are probably related to generally lower sample sizes and hence higher levels of sampling error for South Australia.

The model is able to mimic the recent pattern in tag recaptures for Bass Strait adequately (Fig. 7 upper panels). However, the model over-estimates the number of recaptures during the 1970s. Whether this is a consequence of poor choices for the tag-reporting rates or a structural problem with the underlying population dynamics model is, however, unclear. Tagging data are only available from 1993 for South Australia. While the model mimics the 
trend in recaptures well (Fig. 7 lower panels), in view of the shorter period for which recaptures are available, this is not particularly noteworthy.

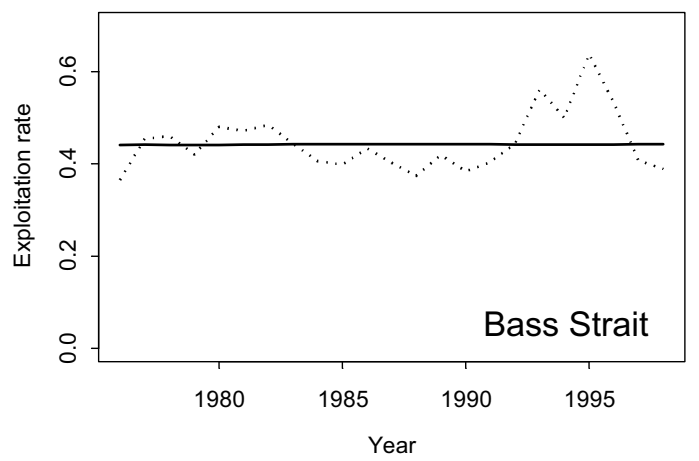

\section{The base-case assessments}

The results of the assessments are summarized by the values for the following five quantities of interest to man-

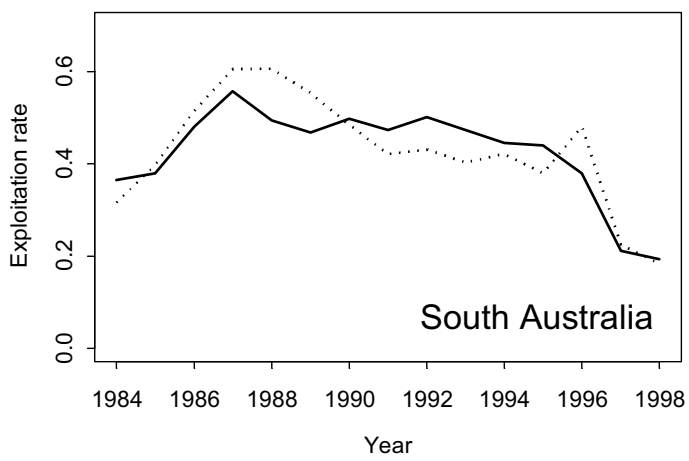

Fig. 4. Estimated exploitation rate time-trajectory (dotted line) and the values inferred from the effort information through Equation (B2.c) (solid line) for Bass Strait (6 inch mesh) and South Australia (7 inch mesh).
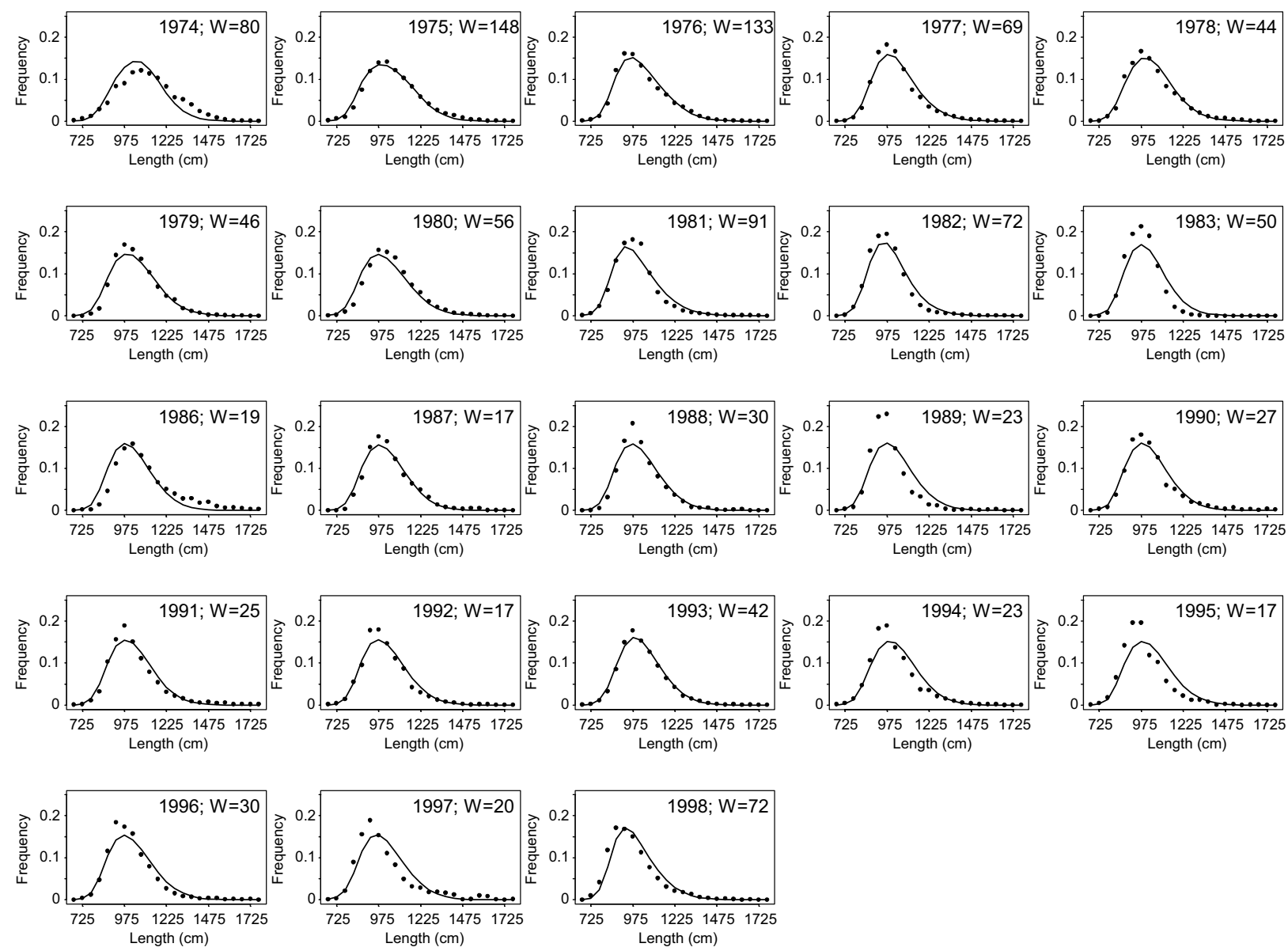

Fig. 5(a). Observed (dots) and model-predicted (solid lines) female length-frequency data for 6 inch mesh catches in Bass Strait. The value of $\mathrm{W}$ indicates the relative weight assigned to the data for each year. 

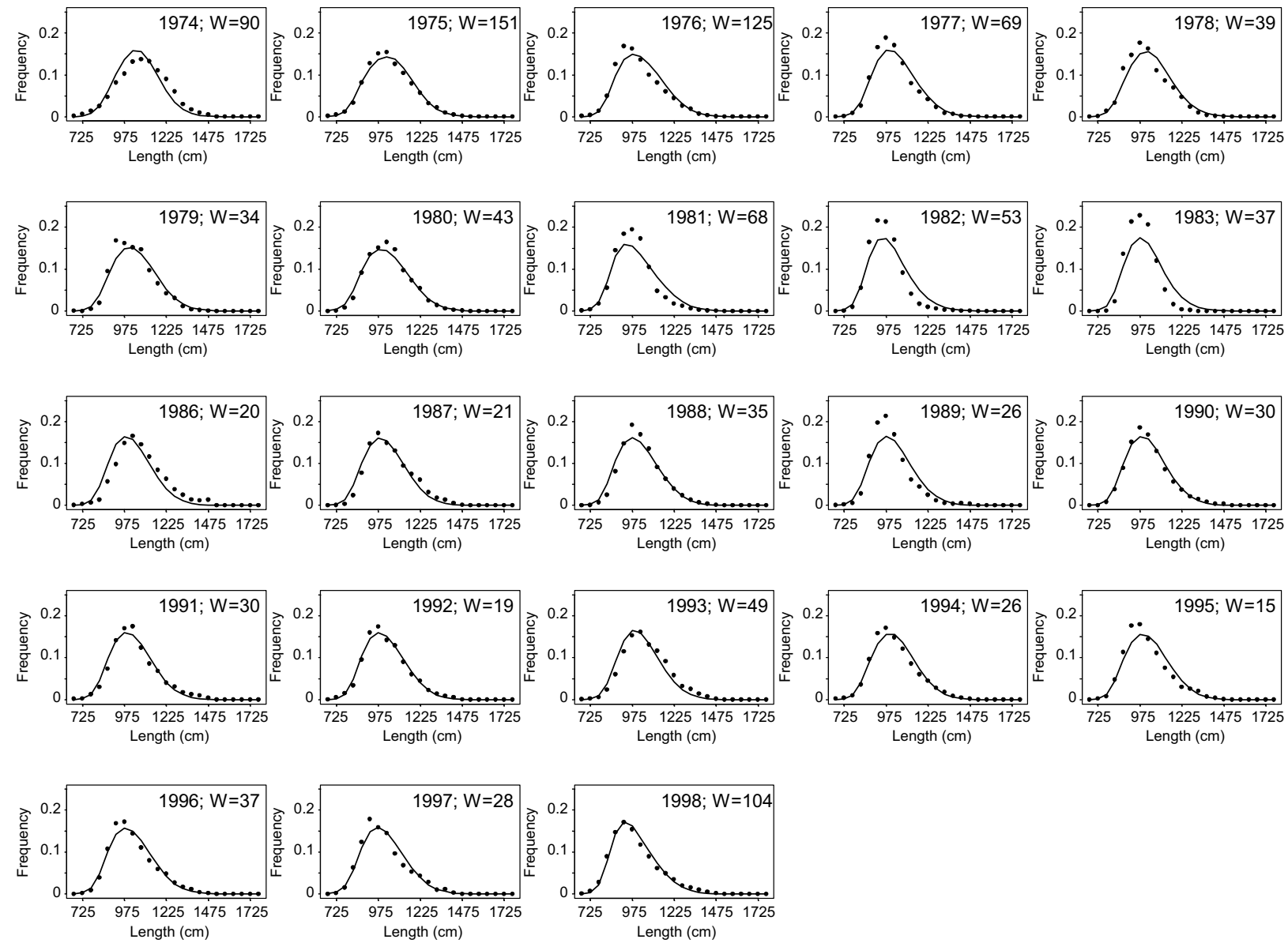

Fig. 5(b). Observed (dots) and model-predicted (solid lines) male length-frequency data for 6-inch mesh catches in Bass Strait. The value of $\mathrm{W}$ indicates the relative weight assigned to the data for each year.

agement, the negative of the logarithm of the likelihood function (ignoring constants independent of the model parameters), $-\ell n, L$, in addition to time-trajectories of the size of various components of the population:

$S B_{0}$ is the pup production in a virgin state,

$M_{2} \quad$ is the instantaneous rate of natural mortality for fish of age 2 and older (at pre-exploitation equilibrium when natural mortality is densitydependent),

$M S Y R$ is the $M S Y$ rate,

$S B_{73} / S B_{0}$ is the ratio of the pup production in 1973 to that in a virgin state, expressed as a percentage, and

$S B_{99} / S B_{0}$ is the ratio of the pup production in 1999 to that in a virgin state, expressed as a percentage.

Note that the values for availability as a function of length, the rate of natural mortality for $2+$ animals, $M_{2}$, and the $M S Y$ rate, $M S Y R$, are treated as estimable parameters for the assessments for Bass Strait (constrained to pre-specified ranges in the cases of $M_{2}$ and MSYR). In contrast, the assessments for the populations of gummy shark off South Australia are based on the values for (1) availability as a function of length, (2) $M_{2}$, and (3) $M S Y R$ derived from the base-case assessment for Bass Strait. The estimates of $M_{2}$ and MSYR ( 0.188 and 0.221 respectively - Table 2) for Bass Strait indicate a relatively short-lived but productive species. The estimate of $M_{2}$ is slightly lower than would have been expected from previous studies (e.g. Walker, 1994a, 1994b; Walker et al., MS 2000) although the present assessment is based on a larger data set than those used in previous assessments. While the estimate of $M_{2}$ is relatively precise ( $90 \%$ confidence interval [0.17, $0.21]$ ), this is not the case for $M S Y R$, the $90 \%$ confidence interval for which ranges from 0.14 to 0.28 . The data for South Australia provide little information about the value of MSYR (although lower rather than higher values are preferred) (Table 3 ). 

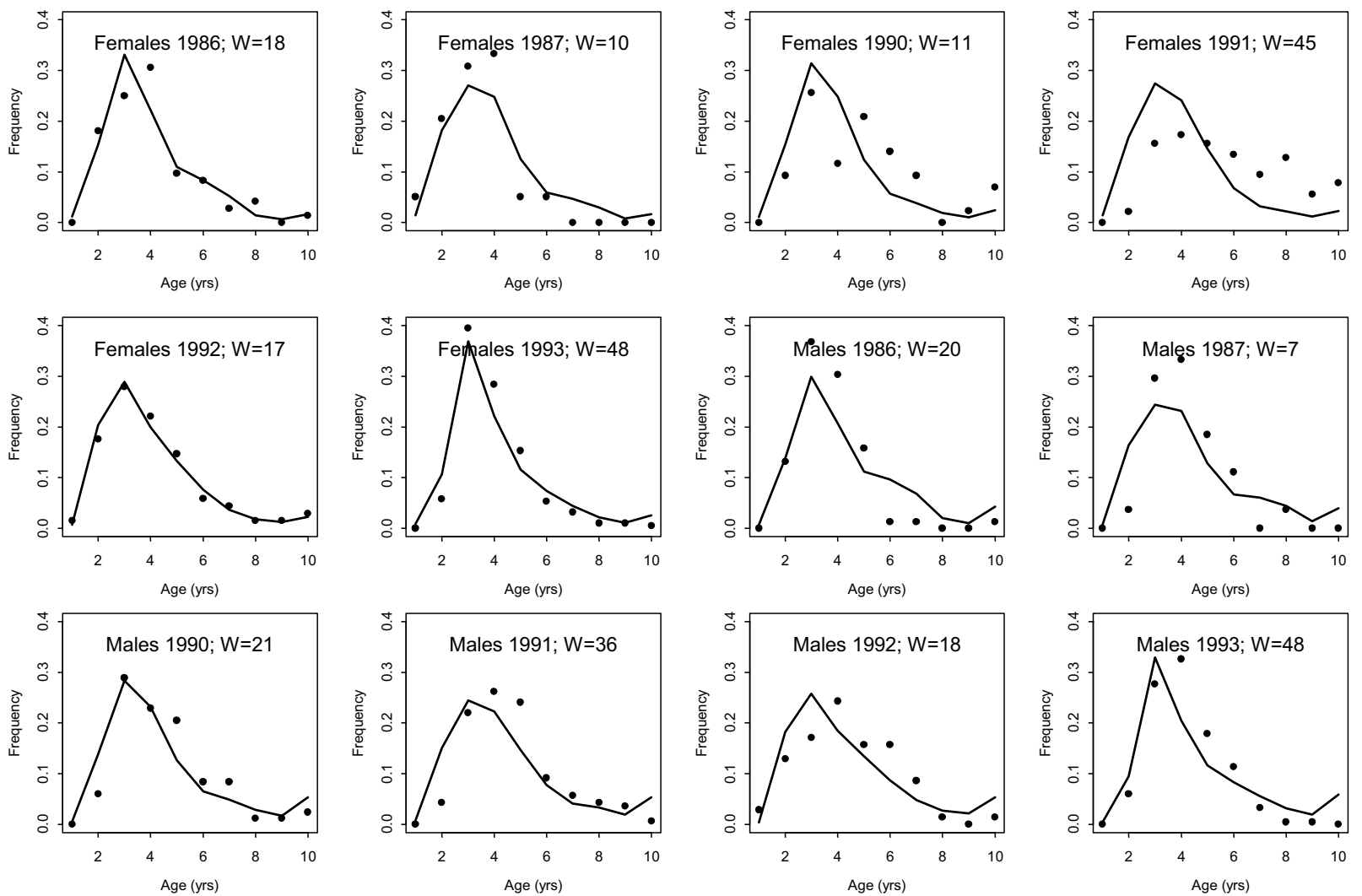

Fig. 6. Observed (dots) and model-predicted (solid lines) age-composition data (6 in mesh catches) in Bass Strait. Results are shown separately for females and males. The value of $\mathrm{W}$ indicates the relative weight assigned to the data for each year.
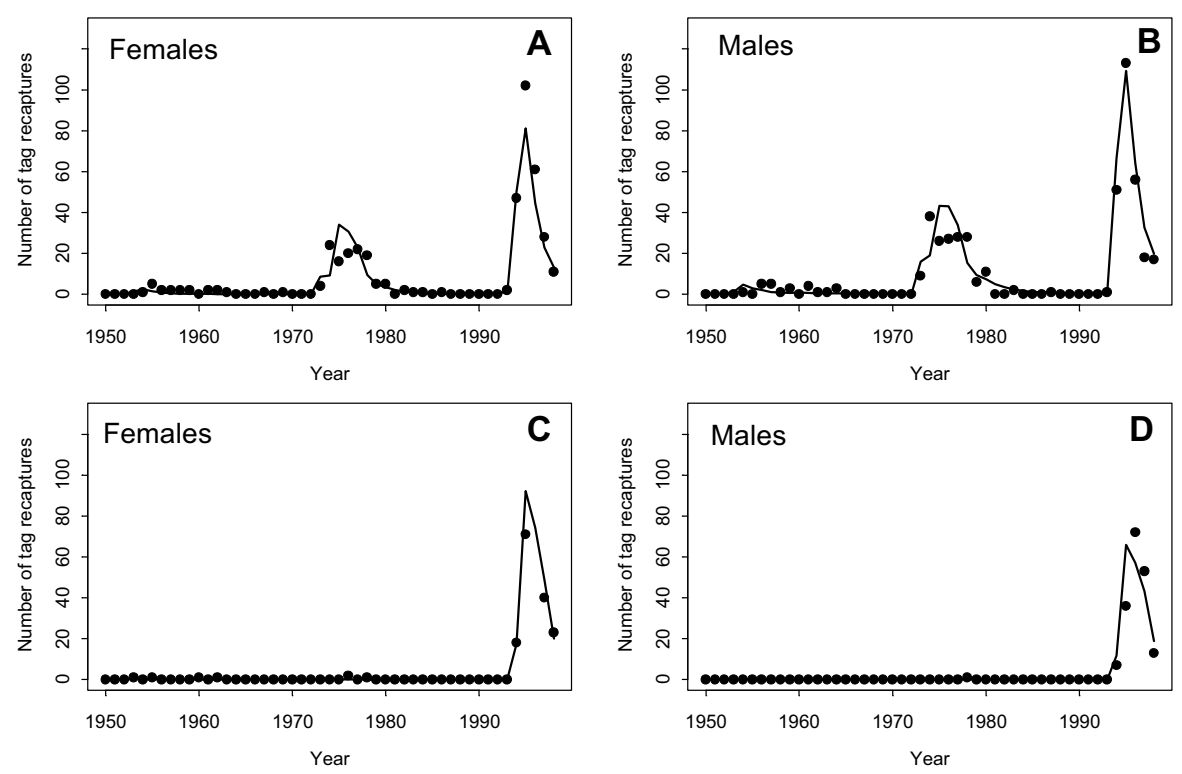

Fig. 7. Observed (dots) and model-predicted (solid lines) number of tag recaptures in Bass Strait (A and B) and off South Australia (C and $\mathbf{D})$. 
TABLE 2. Maximum likelihood estimates of various management-related quantities for gummy shark in Bass Strait. Asterisks indicate sensitivity tests for which the negative loglikelihood is not comparable with that for the base-case analysis.

\begin{tabular}{lcccccc}
\hline \hline \multirow{1}{*}{ Scenario } & \multicolumn{7}{c}{ Quantity } \\
\cline { 2 - 7 } & $S B_{0}$ & $M_{2}$ & MSYR & $S B_{73} / S B_{0}$ & $S B_{99} / S B_{0}$ & $-\ell n L$ \\
\hline Base-case & 7055 & 0.188 & 0.221 & 77.2 & 73.6 & 294.97 \\
Higher catches & 7801 & 0.190 & 0.187 & 74.9 & 70.4 & 293.18 \\
With 73-75 CPUE data & 7404 & 0.181 & 0.248 & 79.1 & 76.7 & 301.31 \\
Alter effort relationship & 6828 & 0.190 & 0.225 & 76.7 & 73.2 & 295.69 \\
Dens-dep M (ages 0-4) & 7712 & 0.169 & 0.296 & 71.4 & 59.6 & 290.41 \\
Dens-dep pups & 6096 & 0.174 & 0.190 & 81.0 & 66.4 & 284.10 \\
No age/length data & 4636 & 0.223 & 0.186 & 70.0 & 54.5 & $74.46^{*}$ \\
No age data & 6736 & 0.190 & 0.212 & 75.4 & 70.2 & $239.43^{*}$ \\
No 7-inch mesh & 3559 & 0.256 & 0.187 & 65.5 & 44.8 & $112.24^{*}$ \\
No CPUE data & 7292 & 0.191 & 0.208 & 77.5 & 73.4 & $378.81^{*}$ \\
No tagging data & 6622 & 0.136 & 0.300 & 75.5 & 69.0 & $158.72^{*}$ \\
30 day early captures & 6441 & 0.192 & 0.223 & 75.9 & 71.1 & $286.43^{*}$ \\
120 day early recaptures & 8134 & 0.182 & 0.222 & 79.2 & 77.8 & $309.46^{*}$ \\
Uniform availability & 2229 & 0.295 & 0.287 & 54.6 & 53.5 & 429.80 \\
Restricted availability & 2235 & 0.295 & 0.282 & 54.5 & 53.0 & 429.33 \\
Deterministic recruitment & 8650 & 0.183 & 0.137 & 79.4 & 59.0 & 377.03 \\
\hline
\end{tabular}

Figures 8 and 9 show base-case time-trajectories (with asymptotic $90 \%$ confidence intervals) for the total (1+) biomass, the pup production, the number of 1-yearolds, and the number of 3-year-olds for Bass Strait and South Australia, respectively. For Bass Strait, there is a gradual reduction in pup production over the period $1927-98$ such that the current pup production is $76 \%$ [90\% CI 63-79\%] of the virgin level. In contrast, the time-trajectory of $(1+)$ biomass for this region is more stable due to a large increase from 1970 to 1980 . This increase is a consequence of a large 1968 year-class. Such a year-class is needed to fit the high mean catch lengths during the early 1970 s, as these can only be explained by a strong cohort passing through the population. The oscillations in total (1+) biomass are mirrored in the timetrajectories of age 1 and age 3 abundance (Fig. 8). The combination of variation in pup survival (Fig. 10) and density-dependence $(V=0.794)$ implies that recruitment to the fishery in Bass Strait has been relatively constant except for a spike corresponding to the 1968 year-class (Fig. 8, bottom right panel). A consequence of this is that exploitable biomass from 1976-98 has been more stable than total biomass or pup production (Fig. 10). The marked increase in exploitable biomass from 1970 to 1973 is due to recruitment to the fishery of the strong 1968 cohort. The exploitable biomass is estimated to have declined from 1990 to 1996 but then to have recovered due primarily to lower fishing mortality.
The population off South Australia is assessed to be currently between 74 and $78 \%$ of the virgin level (in terms of pup production). However, poor pup survival from 1990 has meant that recruitment during the mid- to late-1990s has been weak (Fig. 9). This has lead to a marked decline in total (1+) biomass (panel a of Fig. 9) and in recruited biomass in recent years. The impact of poor recruitment is evident from the length-frequency data - the mean length of the catch increased markedly from 1992. The estimates of pup survival and consequently of recruitment for South Australia are, however, highly imprecise until the late-1970s. This is due to a lack of length-frequency data prior to 1984 .

The result that the population is estimated to be currently more than $70 \%$ of its virgin size in both Bass Strait and off South Australia (Tables 2 and 3) is a direct consequence of the estimated availability and selectivity patterns (Fig. 11). These imply that only a relatively small fraction of the population is vulnerable to the fishery at any one time. One consequence of a significant size-specific availability effect is that the fishery is more susceptible to periods of good and poor recruitment than would be a fishery that had access to all age- and length-classes. Furthermore, the apparent resilience of the population to (over) fishing can be attributed in no small part to this effect. It seems likely that if the fishery changes its behavior so that non-traditional grounds become fished with 
TABLE 3. Maximum likelihood estimates of various management-related quantities for gummy shark off South Australia. Results are shown for three alternative values for the MSYR parameter for each assessment scenario. The results in this table all pertain to the choice $\left(M_{2}=0.188 \mathrm{yr}^{-1}\right)$. Asterisks indicate sensitivity tests for which the negative log-likelihood is not comparable with that for the base-case analysis.

\begin{tabular}{lccccc}
\hline \hline \multirow{2}{*}{ Scenario } & \multicolumn{5}{c}{ Quantity } \\
\cline { 2 - 6 } Base-case & $S B_{0}$ & MSYR & $S B_{73} / S B_{0}$ & $S B_{99} / S B_{0}$ & $-\ell n L$ \\
& 5446 & 0.221 & 82.3 & 76.3 & 167.01 \\
& 5582 & 0.190 & 81.1 & 73.9 & 166.27 \\
Dens-dep pups & 5344 & 0.250 & 83.2 & 78.3 & 167.65 \\
& 4234 & 0.221 & 77.9 & 68.2 & 185.95 \\
No age/length data & 4452 & 0.190 & 76.4 & 67.8 & 183.05 \\
& 4032 & 0.250 & 78.5 & 69.1 & 188.66 \\
No age data & 4499 & 0.221 & 73.3 & 56.2 & $33.18^{*}$ \\
& 4687 & 0.190 & 72.1 & 53.7 & $32.79^{*}$ \\
No CPUE data & 4359 & 0.250 & 74.3 & 58.3 & $33.52^{*}$ \\
& 5181 & 0.221 & 81.8 & 76.9 & $108.39^{*}$ \\
& 5323 & 0.190 & 80.5 & 74.4 & $107.79^{*}$ \\
No tagging data & 5072 & 0.250 & 82.7 & 78.8 & $108.90^{*}$ \\
& 5371 & 0.221 & 82.0 & 76.3 & $222.90^{*}$ \\
Deterministic recruitment & 5515 & 0.190 & 80.8 & 73.9 & $222.37^{*}$ \\
& 5263 & 0.250 & 82.8 & 78.2 & $223.31^{*}$ \\
& 7928 & 0.221 & 88.5 & 86.6 & $104.36^{*}$ \\
& 7896 & 0.190 & 87.4 & 84.3 & $104.00^{*}$ \\
& 4579 & 0.250 & 89.4 & 88.3 & $104.66^{*}$ \\
& 450 & 0.190 & 76.4 & 63.4 & 200.46 \\
& & 0.250 & 78.5 & 68.0 & 203.60 \\
\hline & & & & &
\end{tabular}
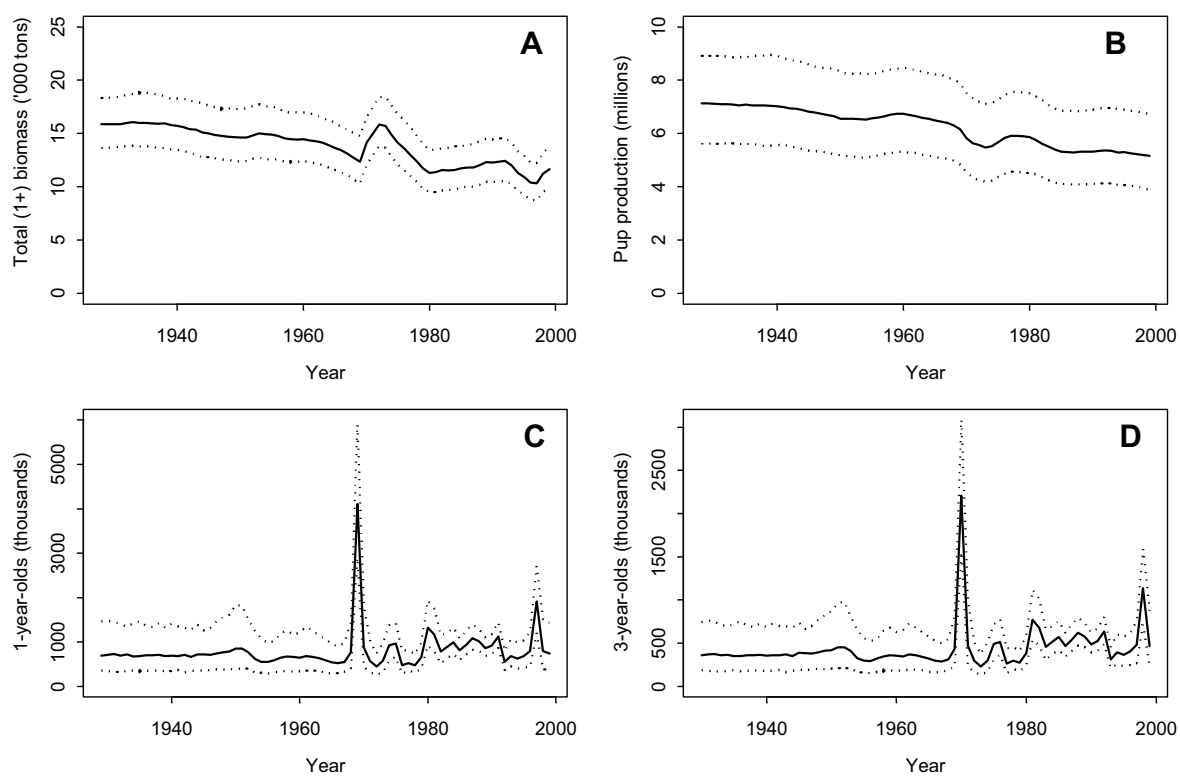

Fig. 8. Base-case time-trajectories for Bass Strait (with $90 \%$ confidence intervals) for (A) 1+ biomass, (B) pup production, (C) number of 1-year-olds, and (D) number of 3year-olds. 

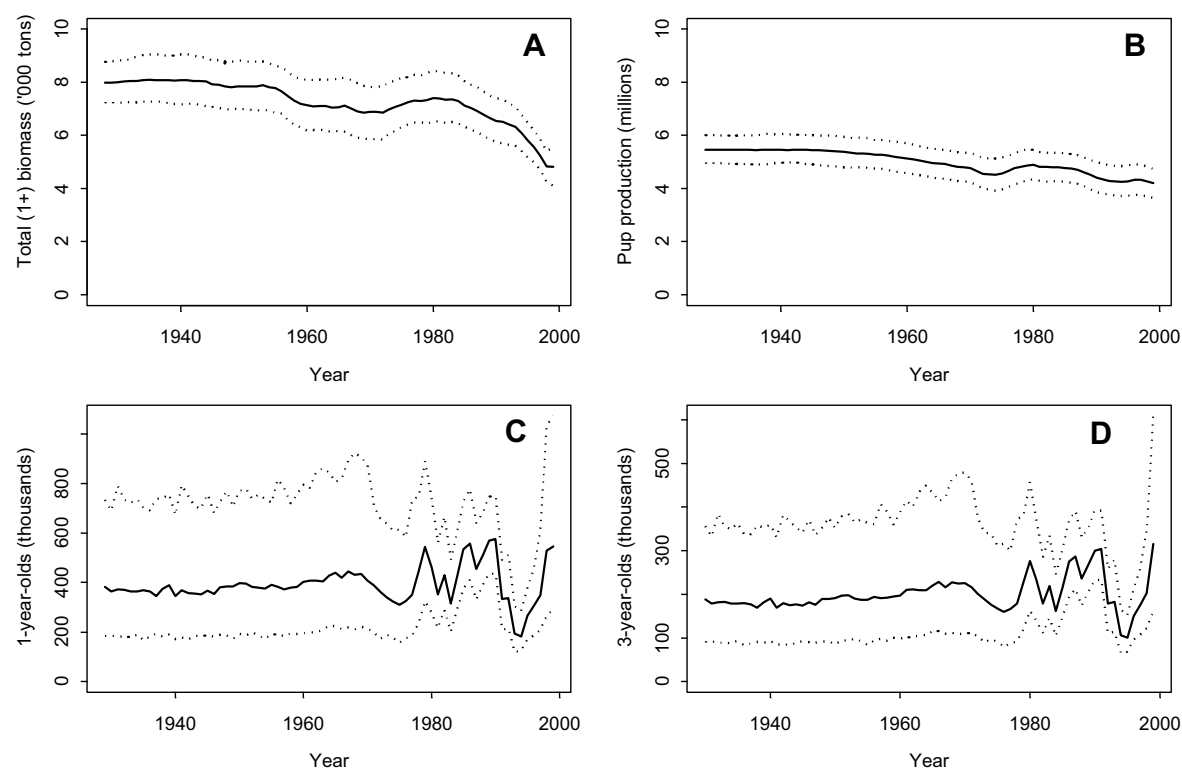

Fig 9. Base-case time-trajectories for South Australia (with $90 \%$ confidence intervals) for (A) 1+ biomass, (B) pup production, (C) number of 1 year-olds, and (D) number of 3 year-olds.
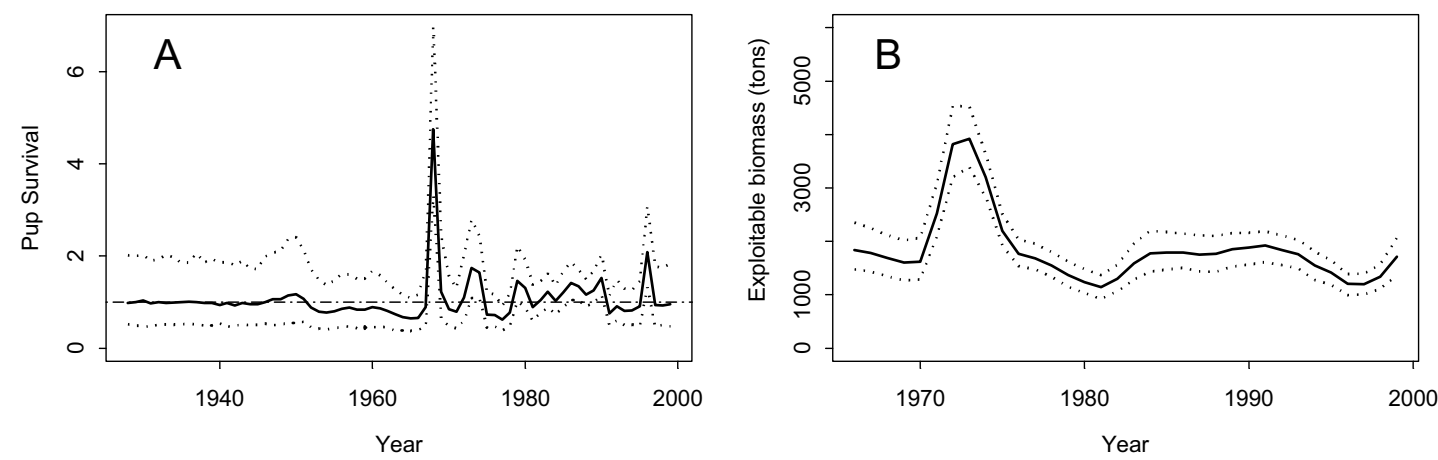

Fig. 10. (A) Annual pup survival for Bass Strait based on the base-case assessment, expressed as fraction of that expected under the deterministic stock-recruitment relationship (with $90 \%$ confidence intervals) and (B) the time-trajectory for Bass Strait (with 90\% confidence intervals) for the biomass available to 6-inch mesh gear.
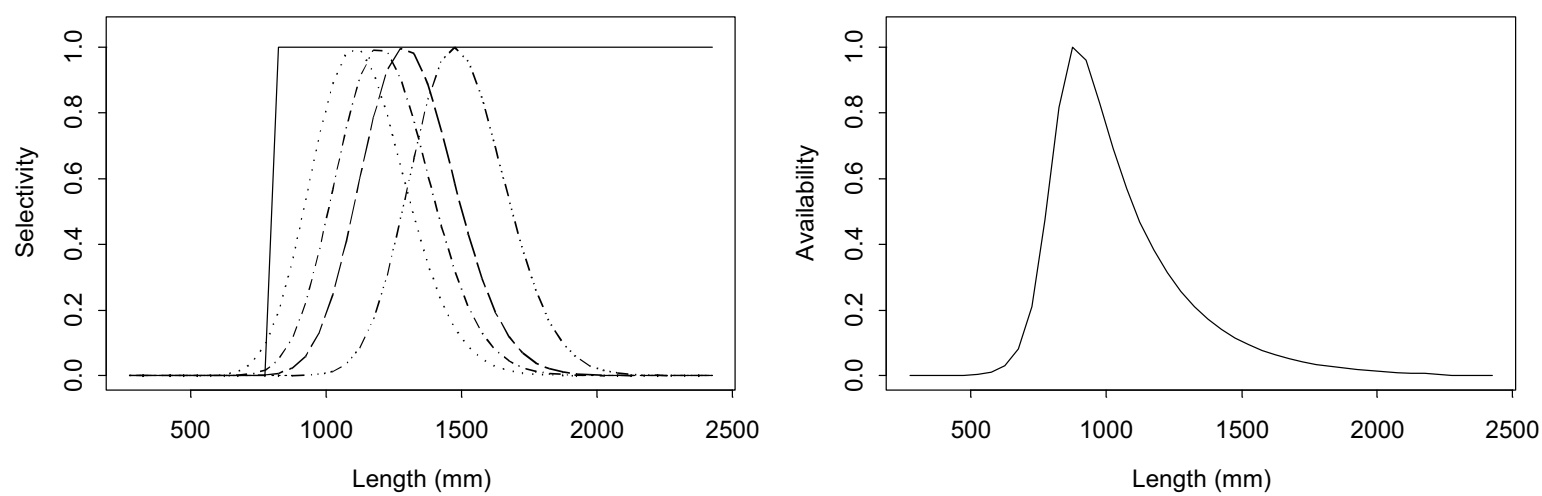

Fig. 11. Selectivity against length and the availability function estimated for the base-case assessment. 
increasing frequency, this resilience may be substantially reduced.

\section{Sensitivity tests}

The bulk of sensitivity tests (Tables 2 and 3) focus on the assessment for Bass Strait because it is clear that the data for South Australia are fairly uninformative, except for the final years of the assessment period.

Making allowance for the possibility that the historical catches in Bass Strait underestimate the true removals due to fishing (sensitivity test 'Higher catches' in Table 2) leads, as expected, to a lower current depletion in 1973 (in terms of pup production) and a less productive stock (the estimate of MSYR drops from its base-case value of 0.22 to 0.19 for this sensitivity test). The importance of the latter result should be interpreted with caution because MSYR is determined rather imprecisely. There is a slightly (though non-significant) improvement to the fit to the data (a decrease in the negative log-likelihood of 1.79 compared to the base-case assessment) if the historical catches are changed. Catch and effort data are available for 1973-75 but these were omitted from the base-case catch-effort standardization because of concerns regarding (extreme) mis-reporting during the early (and most effectively policed) period of the 'mercury ban'. Including the catch-rates for 1973-75 in the assessment for Bass Strait (sensitivity test 'With 73-75 CPUE data' in Table 2) has little impact - a slightly less depleted and more productive resource.

The results for Bass Strait are largely insensitive to changing the approach used to model the fishing effort - fishing mortality relationship from Equation (B.2c) to Equation (B.2b) (sensitivity test 'Alter effort relationship'). This result is not very surprising because the model estimates that the exploitation rate from 1976-98 has been independent of fishing effort and both Equations (B.2b) and (B.2c) converge to this limit.

Two of the sensitivity tests examine the implications of changing how density-dependence is included in the assessment. The results are sensitive to this. For example, assuming that density-dependence acts only on pup survival when assessing the population in Bass Strait (Table 2, row 'Dens-dep pups') leads to the lowest value for the negative log-likelihood in Table 2 (a highly significant reduction from the base-case value of 10.9). This improvement is due to an improved fit to the length-frequency data. However, this assumption also leads to somewhat unrealistic (near oscillatory) time-trajectories of population size (Fig. 12) because assuming that density-dependence is

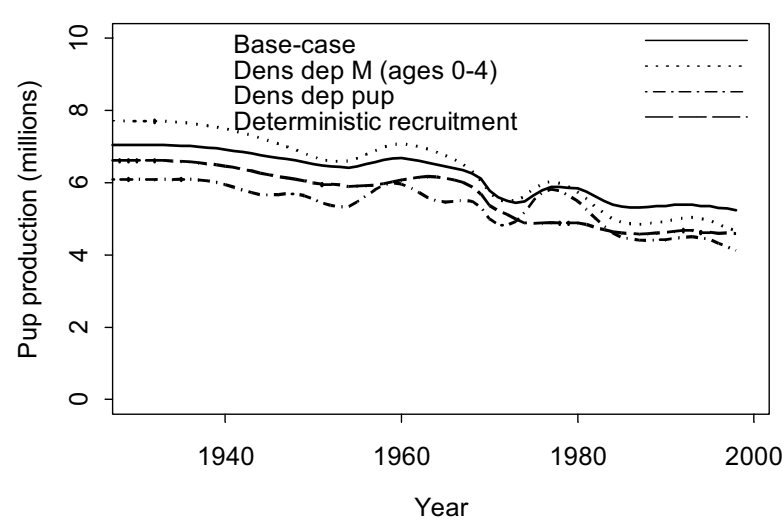

Fig. 12. Time-trajectories of pup production for Bass Strait for the base-case assessment, for two sensitivity tests that change how density-dependence is included in the assessment and for the sensitivity test that assumes that pup production is related deterministically to the number of pregnant females.

functionally related to pup production increases the timelags in the model and hence the possibility of oscillatory behavior. Unrealistic behavior of models for long-lived animals based on the assumption that density-dependence impacts juvenile survival rate is well known (e.g. Givens et al., 1995). Assuming that density-dependence acts on natural mortality for only ages $0-4$ reduces the modelinduced variability in pup production and also reduces the improvement in fit substantially (the difference between the negative log-likelihood for the base-case assessment and "Dens-deep $M$ age $0-4$ " sensitivity test is 4.56 ). The result that improved fits occur when density-dependence is assumed to act only on pups is not general, however. For example, assuming that density-dependence acts only on pups (0 year-olds) leads to significantly poorer fits to the data for South Australia (Table 3).

Ignoring the length-frequency and age-composition data (rows 'No age/length data' in Tables 2 and 3) leads to a lower estimate for $M S Y R$ and a higher estimate for $M_{2}$ for Bass Strait. It also leads to the conclusion that the pup production was more depleted in 1999 than suggested by the base-case assessment (55\% and 56\% compared to 74\% and $76 \%$ for Bass Strait and South Australia, respectively). As expected, the $90 \%$ intervals for 1 year-old and 3 yearold abundance are wider when the length-frequency and age-composition data are omitted from the assessment (see Fig. 13 for the results for Bass Strait). The results in Fig. 13 are notable in that the years with higher than expected recruitment differed markedly from those in Fig. 8 as the 'No age/length data' sensitivity test is based on mimicking trends in the catch-rate data rather than the length- and age-composition data. 

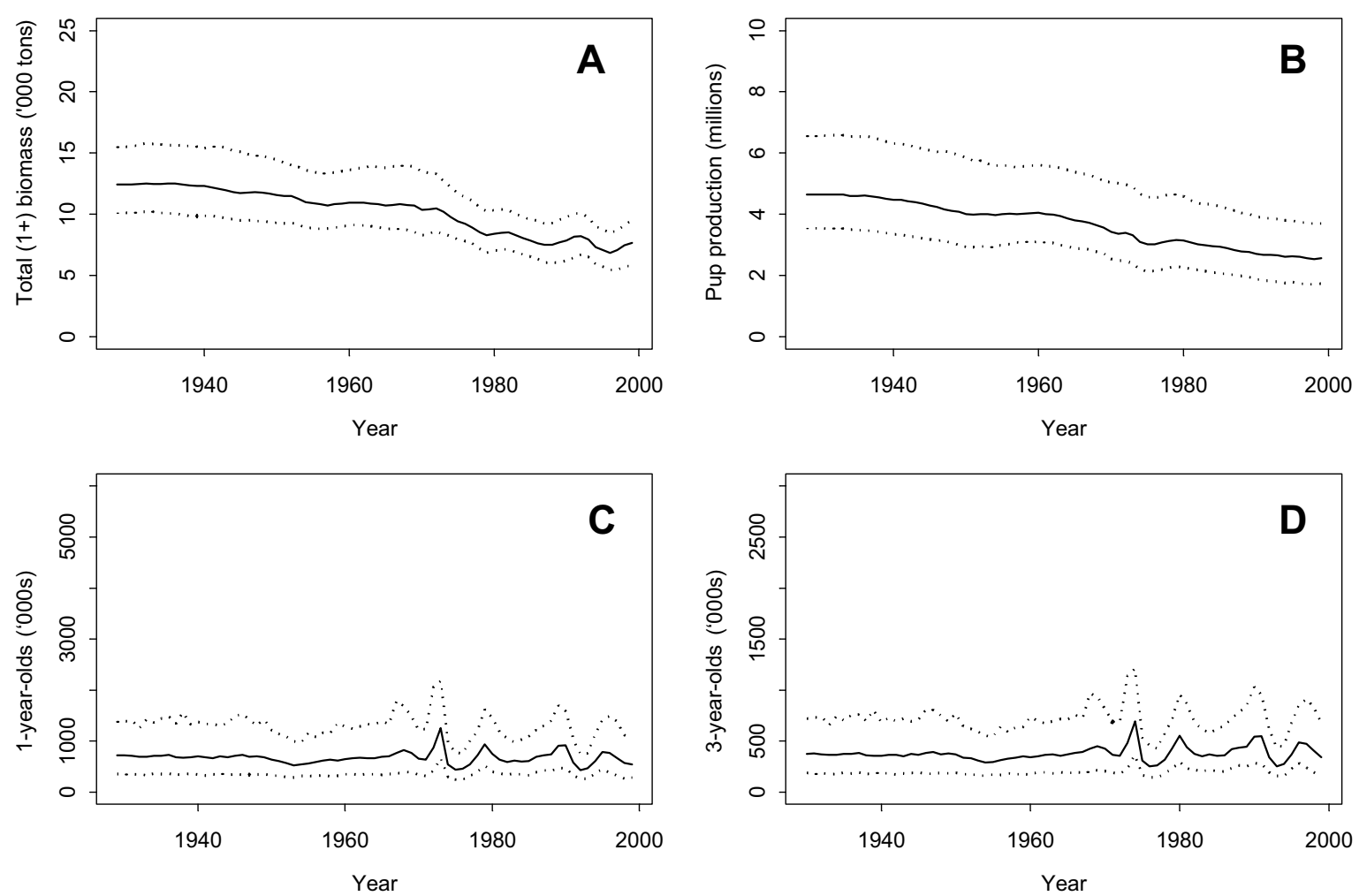

Fig. 13. Time-trajectories for Bass Strait (with 90\% confidence intervals) for (A) $1+$ biomass, (B) pup production, (C) number of 1 year-olds, and (D) number of 3 year-olds. The scientific results are based on the sensitivity test in which the age- and length-composition dat are ignored.

The results are largely insensitive to ignoring the age-composition data (row 'No age data' in Tables 2 and $3)$. The sensitivity test in which the length-frequency data for 7-in mesh are removed from the Bass Strait assessment (row 'No 7-inch mesh' in Table 2) leads to a higher value for $M_{2}$ and lower values for MSYR and current depletion. It also leads to a lower value for strength of the 1968 yearclass. Omitting the length-frequency data for 7-inch mesh gear is considered because these data relate to a period (1970-74) when fishers' practices may have been quite different from what they were later, so these data may not be representative.

Dropping the catch-rate data (rows 'No CPUE data' in Tables 2 and 3) has little impact on the results of the assessment. This is hardly surprising because the weight assigned to these data in the base-case analysis is low relative to the weight assigned to the other sources of data. Dropping the tagging data (rows 'No tagging data' in Tables 2 and 3) has a marked impact on the results. In particular, for Bass Strait, $M_{2}$ is estimated to be only 0.14 per year while $M S Y R$ is estimated to be equal to its upper bound of 0.3 . This result indicates that the tagging and length-frequency data are 'in conflict' to some extent. The tagging data suggest a higher value for natural mortality whereas the length-frequency data suggest a lower value. This result is consistent with the relatively high estimate for the rate of natural mortality ( 0.28 per year) obtained by Walker et al. (MS 2000) who used only tagging data in their analyses. Reducing the cut-off for 'early recaptures' (see Equations B.7 and B.9) from 60 to 30 days leads to a more depleted population; the opposite effect is evident if the cut-off is increased from 60 to 120 days. This is probably because the recapture rate soon after release may be unreflective of the actual fishing mortality rate because the tagged animals have yet to be become fully mixed into the population and so are somewhat more susceptible to capture soon after release.

Assuming that availability is uniform when conducting an assessment of the Bass Strait population (Table 2, row 'Uniform availability') or forcing availability to be never less than $10 \%$ of the maximum availability (Table 2 , row 'Restricted availability') suggests much higher values for $M_{2}$ and MSYR and a more depleted population. The former result is not surprising - assuming that availability 
depends on length implies that numbers in the catch drop off quickly with length/age; under the assumption of uniform availability, this effect is mimicked by a higher rate of natural mortality. The fits to the age-composition data by the 'Uniform availability' and 'Restricted availability' sensitivity tests are better than those achieved by the base-case analysis. However, this is more than offset by the much poorer fits to the length-frequency data. Consequently, the fits for these two sensitivity tests are highly significantly poorer than that of the base-case assessment.

Assuming that there is no process error and, instead, that the number of pups is related deterministically to the number of pregnant females (sensitivity tests 'Deterministic recruitment' in Tables 2 and 3; i.e. setting $\varepsilon_{t}$ $=0$ in Equation A.3) leads to a significantly poorer fit to the data for Bass Strait. However, the time-trend in pup production is quite similar to that for the base-case analysis (Fig. 12) suggesting that assessments based on deterministic recruitment may nevertheless provide relatively robust estimates of trends in pup production. In contrast, assuming deterministic dynamics when fitting the model to the data for South Australia does not lead to a significantly poorer fit. This is a consequence of the relatively short period for which length-frequency and age-composition data are available.

In summary then, the populations of gummy shark in Bass Strait and off South Australia are both estimated to be currently above the level at which $M S Y$ would be achieved, $B_{M S Y}$, and recruitment to the fisheries in both areas is estimated to be stable. The population in Bass Strait is estimated to be somewhat more depleted than that off South Australia. These qualitative appraisals of the status of the populations are robust to the specifications of the assessment. However, this is not the case for the actual quantitative results. In particular, the results are very sensitive to assumptions about density-dependent processes and the extent to which gummy sharks are unavailable to the fishing gear. Furthermore, two of the key data sources included in the assessment (the tagging and length-frequency data) appear to be in conflict to some extent.

\section{Advantages and disadvantages of the modeling ap- proach}

Apart from the inclusion of a variety of data types, the assessment of gummy shark is novel compared with previous assessments of this species and other shark species in Australia because account is taken of 'gear competition', and 'availability' is included in the model in addition to gear selectivity. Inclusion of the latter, in particular, has a profound impact on the estimates of the current status of the resource in Bass Strait. Ignoring availability is not supported by the existing data (differences in the negative log-likelihood for the base-case assessment and the two sensitivity tests that involve forcing availability to be closer to being uniform are over $130 \log$-likelihood units).

This is the first assessment of gummy shark that has made full use of length-frequency and age-composition data (the assessments by Walker (1994a, 1998) were based on fitting to the data on the mean weight of individuals in the catch while that by Walker (1994b) was based on fitting to the data of the mean length of individuals in the catch). Results for Bass Strait confirm the value of making use of the length-frequency data. These data provide information about the relative strengths of different yearclasses, which is of value in explaining past changes in abundance and of some considerable interest to fishers and managers. It is clear from the results of this method that estimates of the abundance of age 1 animals are very imprecise, except for the years for which length-frequency and age-composition data are available (contrast the 90\% confidence intervals for pup production relative to that expected from the stock-recruitment relationship for the years prior to 1965 and those thereafter).

A further advantage of the availability of a consistent time-series of information from tagging and on the lengthand age-composition of the catches is the ability to examine (and statistically support) more complicated models. For example, it would not have been possible to argue for non-uniform availability without the length-composition information because the sensitivity tests based on uniform and restricted availability actually provide slightly better fits to the catch-rate data. Had a log-likelihood ratio test been used to compare the 'uniform availability' sensitivity test with the base-case analysis when both ignored the length- and age-composition data, it is likely that the simpler 'uniform selectivity' assumption could not have been rejected.

The major disadvantages of the method, apart from the need for substantial quantities of length- and/or agecomposition data, relate primarily to the computational demands associated with estimating $100+$ parameters and the need to select values for some of the model parameters. In this paper, the impact of the choices for the values of these parameters for the base-case assessments is examined by conducting sensitivity analyses and is found 
to be relatively small. However, this is primarily due to the large amount of data available for gummy shark. It is likely that the assessment results for 'data-poor' species will be much more sensitive to the values assumed for these parameters.

\section{Acknowledgements}

Funding for this work was supported by the Fisheries Research and Development Corporation (FRDC) through FRDC grant 99/102 and by the Australian Fisheries Management Authority. Robin Thompson (CSIRO Marine Research) and an anonymous reviewer are thanked for their comments on a draft of this paper.

\section{References}

BEDDINGTON, J. R., and J. G. COOKE. 1983. The potential yield of fish stocks. FAO Fish. Tech. Pap., 242, 47 p.

BROWN, L. P., and T. I. WALKER. MS 1999. Tag reporting rates for gummy shark and school shark estimated from catch and from tags per unit catch. SharkFAG Doc., No. SSFAG/99/D11, (available from the Australian Fisheries Management Authority, Canberra).

GIVENS, G. H., J. E. ZEH, and A. E. RAFTERY. 1995. Assessment of the Bering-Chukchi-Beaufort Seas stock of bowhead whales using the BALLEEN II model in a Bayesian synthesis framework. Rep. Int. Whal. Commn., 45: 345-364.

HILBORN, R. 1990. Determination of fish movement patterns from tag recoveries using maximum likelihood estimators. Can. J. Fish. Aquat. Sci., 47: 635-643.

KIRKWOOD, G. P., and T. I. WALKER. 1986. Gill net mesh selectivities for gummy shark, Mustelus antarcticus Günther, taken in south-eastern Australian waters. Aust. J. Mar. Freshw. Res., 37: 689-697.

MCDONALD, C. M. 1988. Genetic variation, breeding structure and taxonomic status of the gummy shark Mustelus antarcticus in southern Australian waters. Aust. J. Mar. Freshw. Res., 39: 641-648.

MOULTON, P. M., T. I. WALKER, and S. R. SADDLIER. 1992. Age and growth studies of gummy shark, Mustelus antarcticus Günther, and school shark, Galeorhinus galeus (Linnaeus), from southern-Australian waters. Aust. J. Mar. Freshw. Res., 43: 1241-1267.

PATTERSON, K., R. COOK, C. DARBY, S. GAVARIS, L. KELL, P. LEWY, B. MESNIL, A. PUNT, V. RESTREPO, D. W. SKAGEN, and G. STEFANSSON. 2001. Estimating uncertainty in fish stock assessment and forecasting. Fish and Fisheries, 2: 125-157.

PRINCE, J. D. MS 1992. Stock assessment and fisheries management in the southern Australian shark fishery: An independent perspective. SharkFAG Doc., No. SharkFAG/99/D17, (available from the Australian Fisheries Management Authority, Canberra), $23 \mathrm{p}$.

PUNT, A. E., and T. I. WALKER. 1998. Stock assessment and risk analysis for the school shark (Galeorhinus galeus) resource off southern Australia. Mar. Freshw. Res., 49: 719-731.

PUNT, A. E., F. PRIBAC, T. I. WALKER, and B. L. TAYLOR. MS 2001b. Population modeling and harvest strategy evaluation for school and gummy shark. Final report to the Fisheries Research and Development Corporation, Project No 99/102, (CSIRO Marine Research, Hobart, Tasmania, Australia).

PUNT, A. E., F. PRIBAC, T. I. WALKER, B. L. TAYLOR, and J. D. PRINCE. 2000a. Stock assessment of school shark Galeorhinus galeus based on a spatially-explicit population dynamics model. Mar. Freshw. Res., 51: 205-220.

PUNT, A. E., D. C. SMITH, R. B. THOMSON, M. HADDON, X. HE, and J. M. LYLE. 2001a. Stock assessment of the blue grenadier Macruronus novaezelandiae resource off south-eastern Australia. Mar. Freshw. Res., 52: 701-717.

PUNT, A. E., T. I. WALKER, B. L. TAYLOR, and F. PRIBAC. 2000b. Standardization of catch and effort data in a spatially-structured shark fishery. Fish. Res., 45: 129-145.

SMITH, A. D. M., and A. E. PUNT. 1998. Stock assessment of gemfish (Rexea solandri) in eastern Australia using maximum likelihood and Bayesian methods. In: Fisheries Stock Assessment Models. T. J. Quinn II, F. Funk, J. Heifetz, J. N. Ianelli, J. E. Powers, J. F. Schweigert, P. J. Sullivan and C-I Zhang (eds.), Alaska Sea Grant College Program, AK-SG-98-01, p. 245-286.

SMITH, D. C., A. D. M. SMITH, and A. E. PUNT. 2001. Approach and process for stock assessment in the South East Fishery, Australia: a perspective. Mar. Freshw. Res., 52: 671-681.

WALKER, T. I. 1983. Investigations of the gummy shark, Mustelus antarcticus Günther, from south-eastern Australian waters. Report to Fishing Industry Research Committee. June 1983. In: Proceedings of the Shark Assessment Workshop, South East Fisheries Committee Shark Research Group. A. E. Caton (ed.). 7-10 March 1983. Melbourne, (Department of Primary Industry: Canberra.), p. 1-94.

1986. Southern shark assessment project. Second review. Mar. Sci. Lab. Prog. Rev., 66.

1992. A fishery simulation model for sharks applied to the gummy shark, Mustelus antarcticus Günther, from southern Australian waters. Aust. J. Mar. Freshw. Res., 43: 195-212.

1994a. Fishery model of gummy shark, Mustelus antarcticus, for Bass Strait. In: Resource Technology '94 New Opportunities Best Practice. I. Bishop (ed.), 26-30 September 1994, (The Centre for Geographic Information Systems and Modelling, the University of Melbourne: Melbourne), p. 422-438.

1994b. Stock assessments of the gummy shark, Mustelus antarcticus Günther, in Bass Strait and off South Australia. In: Population Dynamics for Fisheries Management. D.A. Hancock (ed.) 24-25 August 1993, Perth. 1, (Australian Government Printing Service: Canberra), p. 173-187.

1998. Can shark resources be harvested sustainably? A question revisited with a review of shark fisheries. Mar. Freshw. Res., 49: 553-572. 
WALKER, T. I., P. L. MOULTON, and S. R. SADDLIER. MS 1989. Reproduction studies of four species of shark and one species of elephant fish commercially fished in southern Australia. Southern Shark Assessment Project - Final FIRTA Report, (Marine and Fisheries Resources Institute, Queenscliff, Victoria, Australia), $45 \mathrm{p}$.

WALKER, T. I., B. L. TAYLOR, and L. P. BROWN. MS 2000. Southern shark tag database project. Final Report to the Fisheries Research and Development Corporation, FRDC Project No. 96/162, (Marine and Fisheries Resources Institute, Queenscliff, Victoria, Australia).

WALKER, T. I., B. L. TAYLOR, and R. J. HUDSON. MS 2002. Southern shark catch and effort 1970-2001 report to Australian Fisheries Management Authority, July 2002 (Marine and Freshwater Resources Institute: Queenscliff,
Victoria, Australia), 47 p.

WARD, R. D., and M. G. GARDNER. MS 1997. Stock structure and species identification of school and gummy sharks in Australian waters. Report to the Fisheries Research and Development Corporation, FRRF Project No 93/11 and FRDC Project No 93/64, February 1997 (CSIRO Marine Research, Hobart, Tasmania, Australia), 92 p.

XIAO, Y. 1996. A framework for evaluating experimental designs for estimating rates of fish movement from tag recoveries. Can. J. Fish. Aquat. Sci., 53: 1272-1280.

XIAO, Y., L. P. BROWN, T. I. WALKER, and A. E. PUNT. 1999. Estimation of instantaneous rates of tag shedding for school shark, Galeorhinus galeus, and gummy shark, Mustelus antarcticus, by conditional likelihood. Fish Bull U.S., 97: 170-184. 



\section{APPENDIX A: The population dynamics model}

\section{Basic Dynamics}

The population dynamics of gummy shark are assumed to be governed by the equation:

$$
N_{g, t+1, a}= \begin{cases}N_{g, t+1,0} & a=0 \\ \left(N_{g, t, a-1} e^{-M_{t, a-1} / 2}-C_{g, t, a-1}\right) e^{-M_{t, a-1} / 2} & 1 \leq a<x \\ N_{g, t, x-1} e^{-M_{t, x-1}}-C_{g, t, x-1} e^{-M_{t, x-1} / 2}+N_{g, t, x} e^{-M_{t, x}}-C_{g, t, x} e^{-M_{t, x} / 2} & a=x\end{cases}
$$

where $N_{g, t, a} \quad$ is the number of fish of age $a$ and sex $g$ ( $g=1$ for females; $g=2$ for males) at the start of year $t$,

$M_{t, a} \quad$ is the instantaneous rate of natural mortality on fish of age $a$ during year $t$,

$C_{g, t, a} \quad$ is the catch (in number) during year $t$ of fish of age $a$ and sex $g$ :

$$
C_{g, t, a}=\sum_{j} C_{g, t, a, j}
$$

$C_{g, t, a, \mathrm{j}} \quad$ is the catch (in number) during year $t$ by gear-type $j$ of fish of age $a$ and sex $g$, and

$x \quad$ is the maximum age considered (treated as a plus group) - taken to be 30 .

\section{Pup production}

The expected number of pups in a given year depends on the number of mature females, the frequency of pregnancy, and the number of pups (taken here to be the same as the number of embryos) per pregnant female. The latter two quantities are taken to be functions of age. The total number of pups of sex $g$ at the start of year $t+1$ is given by:

$$
N_{g, t+1,0}=0.5 Q_{t+1} \Gamma_{t+1} e^{\varepsilon_{t+1}-\sigma_{r}^{2} / 2}
$$

where $Q_{t}$ is the density-dependent factor that multiplies the number of births during year $t$,

$$
Q_{t}=1+\max \left\{\left(Q_{0}-1\right)\left[1-D_{t} / D_{0}\right], 0\right\}
$$

$Q_{0}$ is the parameter that determines the magnitude of density dependence,

$\Gamma_{t}$ is the number of pups produced during year $t$ :

$$
\Gamma_{t}=\sum_{a=1}^{x} P_{a}^{\prime} P_{a}^{\prime \prime} N_{1, t, a}
$$

$D_{t}$ is the size of the component of the population on which density-dependence acts, assumed to be the total (1+) biomass at the start of year $t, B_{t}^{1+}$ :

$$
B_{t}^{1+}=\sum_{a=1}^{x} \sum_{L} \sum_{g} w_{g, L} \Phi(g, a+1 / 2, L) N_{g, t, a}
$$

$\varepsilon_{t} \quad$ is the logarithm of the ratio of the expected and actual number of pups,

$$
\varepsilon_{t} \sim N\left(0 ; \sigma_{r}^{2}\right)
$$

$\sigma_{r} \quad$ is the standard deviation of $\varepsilon_{t}$ (assumed to be 0.4 ),

$P_{a}^{\prime} \quad$ is the number of pups per pregnant female of age $a$,

$P_{a}^{\prime \prime} \quad$ is the proportion of females of age $a$ that become pregnant each year,

$w_{g, L} \quad$ is the mass of a fish of sex $g$ in length-class $L$, and

$\Phi(g, a, L)$ is the fraction of animals of age $a$ and sex $g$ that are in length-class $L$. 
The subscript 0 in Equation (A.4) indicates an evaluation of $D$ at the pre-exploitation equilibrium level. Equation (A.4) assumes that all of the density dependence occurs on the mortality between birth and age one, in which case $Q_{0}$ is the expected ratio of the pup survival rate in the limit of zero population size to that at unexploited equilibrium.

The number of pups (actually embryos) per pregnant female of age $a$ (total length $\ell_{1, a}$ ) is given by:

$$
P_{a}^{\prime}= \begin{cases}0 & \ell_{1, a}<995 \mathrm{~mm} \\ e^{a^{\prime}+b^{\prime} \ell_{1, a}} & \text { otherwise }\end{cases}
$$

where $a^{\prime}$ and $b^{\prime}$ are the parameters that govern the relationship between total length and number of pups per pregnant female.

The proportion of female sharks of age $a$ (total length $\ell_{1, a}$ ) that are pregnant each year is given by:

$$
P_{a}^{\prime \prime}=P_{\max }^{\prime \prime}\left(1+\exp \left(-\ln (19) \frac{\ell_{1, a}-\ell_{50}^{\prime \prime}}{\ell_{95}^{\prime \prime}-\ell_{50}^{\prime \prime}}\right)\right)^{-1}
$$

$$
\begin{array}{ll}
\text { where } \quad p_{\max }^{\prime \prime} & \text { is the proportion of very large }\left(\ell_{1, a} \rightarrow L_{\infty, 1}\right) \text { females that are pregnant each year, } \\
& \ell_{50} \quad \text { is the length at which half of the maximum proportion of females are pregnant each year, and } \\
\ell_{95} & \text { is the length at which } 95 \% \text { of the maximum proportion of females are pregnant each year. }
\end{array}
$$

Table A.1 lists the values assumed for the parameters of Equations (A.7) and (A.8).

TABLE A.1. Values for the parameters of the population dynamics model.

(A) Biological parameters

\begin{tabular}{lccl}
\hline \hline Quantity & Female & Male & \multicolumn{1}{c}{ Source } \\
\hline$L_{\infty}(\mathrm{mm})$ & 2019 & 1387 & Moulton et al. (1992) \\
$k\left(\mathrm{yr}^{-1}\right)$ & 0.123 & 0.253 & Moulton et al. $(1992)$ \\
$t_{0}(\mathrm{yr})$ & -1.55 & -0.90 & Moulton et al. $(1992)$ \\
$a\left(\times 10^{-9}\right)$ & 1.22 & 4.38 & Walker (1994a) \\
$b$ & 3.18 & 2.97 & Walker (1994a) \\
$a^{\prime}(\mathrm{yr})$ & -1.8520 & & Walker (1994a) \\
$b^{\prime}\left(\mathrm{yr} r^{-1}\right)$ & 0.0032 & & Walker (1994a) \\
$P_{\max }$ & 0.6060 & & Walker (1994a) \\
$\ell_{50}(\mathrm{~mm})$ & 1273.15 & & Walker (unpubl. data) \\
$\ell_{950}(\mathrm{~mm})$ & 1593.20 & & Walker (unpub. data) \\
\hline
\end{tabular}

(B) Gill-net selectivity parameters (Kirkwood and Walker, 1986)

\begin{tabular}{lcc}
\hline \hline Mesh-size & $\mathrm{a}$ & $\mathrm{b}$ \\
\hline 6 inch & 42.09 & 26.27 \\
7 inch & 56.95 & 22.65 \\
8 inch & 74.08 & 19.90 \\
\hline
\end{tabular}




\section{Catches}

The annual catches are assumed to be taken in a pulse in the middle of the year (after $50 \%$ of the natural mortality) and the fisheries are assumed to be sequential (gauntlet) ${ }^{4}$. The catch (in number) during year $t$ by gear-type $j$ of fish of age $a$ and sex $g$ is calculated from the total catch (in mass) during year $t$ by gear-type $j, \widetilde{C}_{t j}$ :

$$
C_{g, t, a, j}=F_{t, j} \sum_{L} A_{L} S_{g, j, L} \Phi(g, a+1 / 2, L)\left(N_{g, t, a} e^{-M_{t, a} / 2}-\sum_{i=1}^{j-1} C_{g, t, a, i}\right)
$$

where $S_{g, j, L} \quad$ is the selectivity of gear-type $j$ on fish of sex $g$ in length-class $L$,

$A_{L} \quad$ is the availability of a fish of sex $g$ in length-class $L$, and

$F_{t, j} \quad$ is the fully-selected exploitation rate by gear-type $j$ during year $t$ :

$$
F_{t, j}=\tilde{C}_{t, j} /\left(\sum_{g} \sum_{a=1}^{x} \sum_{L} w_{g, L} A_{L} S_{g, j, L} \Phi(g, a+1 / 2, L)\left(N_{g, t, a} e^{-M_{t, a} / 2}-\sum_{i=1}^{j-1} C_{g, t, a, i}\right)\right)
$$

\section{Length and mass}

The (mean) total length of a fish of age $a$ and sex $g$ at the start of the year, $\ell_{g, a}$, is described by the von Bertalanffy growth equation:

$$
\ell_{g, a}=L_{\infty, g}\left(1-e^{-\kappa_{g}\left(a-t_{0, g}\right)}\right)
$$

and the mass by the allometric equation:

$$
w_{g, L}=a_{g}\left(\bar{L}_{L}\right)^{b_{g}}
$$

where $\bar{L}_{L}$ is the mid-point of length-class $L$.

The values assumed for the parameters of Equations (A.11) and (A.12) are listed in Table A.1.

The probability that a fish of age $a$ and sex $g$ lies in length-class $L$ (length-class $L$ is defined to be $[L-\Delta L, L+\Delta L]$ ) is given by:

$$
\Phi(g, a, L)=\int_{L-\Delta L}^{L+\Delta L} \frac{1}{\sqrt{2 \pi} \sigma_{g, a} l} e^{-\frac{\left(\ell n I-\ell n \ell_{g, a}\right)^{2}}{2 \sigma_{g, a}^{2}}} d l
$$

where $\Delta L$ is half the width of a length-class $(25 \mathrm{~cm})$, and

$\sigma_{g, a}$ is (approximately) the coefficient of variation of the length of an animal of age $a$ and sex $g$.

\section{Gear selectivity}

Different selectivity patterns are assumed for the two major gear-types (longlines and gill-nets). The catch by longlines is assumed to be taken uniformly from the $2+$ component of the population (Walker, 1983), i.e.:

$$
S_{g, j, L}= \begin{cases}0 & \bar{L}_{L}<\ell_{g, 2} \\ 1 & \text { otherwise }\end{cases}
$$

The selectivity pattern for gill-nets is assumed to follow a gamma function (Kirkwood and Walker, 1986):

$$
S_{g, j, L}=\left(\frac{\bar{L}_{L}}{\alpha_{g, j} \beta_{g, j}}\right)^{\alpha_{g, j}} e^{\alpha_{g, j}-\frac{\bar{L}_{L}}{\beta_{g, j}}}
$$

where $\alpha, \beta$ are the parameters of the selectivity pattern.

\footnotetext{
4 The impact of assuming that the fisheries act sequentially is unlikely to be large because the annual exploitation rates are relatively
} small. 


\section{Availability}

Availability as a function of length is either assumed to be independent of length or governed by a double-logistic

$$
\begin{aligned}
& A_{L}=A_{L^{\prime}}^{\prime} / \max _{L^{\prime}}\left(A_{L^{\prime}}^{\prime}\right) \\
& A_{L}^{\prime}=\left(1+e^{-\ell n 19\left(\bar{L}_{L}-L_{50}^{A}, 1\right) /\left(L_{95}^{A, 1}-L_{50}^{A, 1}\right)}\right)^{-1}\left(1+e^{-\ell n 19\left(\bar{L}_{L}-L_{50}^{A, 2}\right) /\left(L_{95}^{A, 2}-L_{50}^{A, 2}\right)}\right)^{-1}
\end{aligned}
$$

where $L_{50}^{A, 1}, L_{50}^{A, 2}, L_{95}^{A, 1}, L_{95}^{A, 2}$ are the parameters of the availability function.

\section{Initial conditions}

The population is assumed to have been at pre-exploitation equilibrium at the start of 1927 (the assumed start of harvesting) because there are no data to estimate deviations for the equilibrium age-structure at that time:

$$
N_{g, y_{1}, a}= \begin{cases}0.5 R_{0} e^{-\sum_{a^{\prime}=0}^{a-1} M_{a}{ }^{\prime}} & 0 \leq a \leq x-1 \\ 0.5 R_{0} e^{-\sum_{a^{\prime}=0}^{x-1} M_{a}^{\prime}} /\left(1-e^{-M_{x}}\right) & a=x\end{cases}
$$

where $R_{0} \quad$ is the number of pups at the (deterministic) equilibrium that corresponds to an absence of fishing, and

$y_{1} \quad$ is the first year considered (1927). $B_{0}:$

The value for $R_{0}$ is calculated from the value assumed for the virgin total $(1+)$ biomass at the start of the year,

$$
\begin{aligned}
R_{0}=2 B_{0} / \sum_{g}\left(\sum_{a=1}^{x-1} w_{g, a} e^{-\sum_{a^{\prime}=0}^{a-1} M_{a^{\prime}}}+w_{g, x} \frac{e^{-\sum_{a^{\prime}=0}^{x-1} M_{a^{\prime}}}}{1-e^{-M_{x}}}\right) \\
w_{g, a}=\sum_{L} w_{g, L} \Phi(g, a+1 / 2, L)
\end{aligned}
$$

\section{Natural Mortality}

Natural mortality-at-age is assumed to be governed by the equation:

$$
M_{t, a}= \begin{cases}M_{a}\left(1-V\left(1-D_{t} / D_{0}\right)\right) & 0 \leq a \leq a_{d} \\ M_{a} & \text { otherwise }\end{cases}
$$

where $M_{a}$ is the rate of natural mortality on fish of age $a$ at pre-exploitation equilibrium:

$$
M_{a}= \begin{cases}M_{0} e^{\ln \left(M_{2} / M_{0}\right) a / 2} & 0 \leq a \leq 2 \\ M_{2} & 2<a \leq x\end{cases}
$$

$V$ is the parameter that determines the extent of density-dependence in natural mortality,

$a_{d}$ is the oldest age at which density-dependent natural mortality applies,

$M_{2}$ is the rate of natural mortality on animals aged two and older, and

$M_{0}$ is the rate of natural mortality on pups.

This formalism implies that natural mortality decreases exponentially between age 0 and age 2 , and is constant thereafter. The value for $M_{2}$ is either estimated or pre-specified while the value for $M_{0}$ is calculated so that, in the absence of harvesting, the population satisfies the balance equation:

$$
2=\sum_{a=1}^{x-1} P_{a}^{\prime} P_{a}^{\prime \prime} e^{-\sum_{a^{\prime}=0}^{a-1} M_{a^{\prime}}}+P_{x}^{\prime} P_{x}^{\prime \prime} \frac{e^{-\sum_{a^{\prime}=0}^{x-1} M_{a^{\prime}}}}{1-e^{-M_{x}}}
$$




\section{APPENDIX B: The Contributions to the Likelihood Function}

\section{Catch rate data}

The contribution of the catch-rate data to the likelihood function is based on the assumption that effective effort for gear-type $j$ is lognormally distributed about the exploitation rate:

$$
F_{t, j}=q_{j} f\left(\tilde{C}_{t, j} / l_{t, j}\right) e^{\phi_{j, t}}
$$

where $f(E)$ is relative exploitation rate as a function of actual fishing effort, modeled by one of three alternatives:

$$
\begin{gathered}
f(E)=E \\
f(E)=E^{\gamma} \\
f(E)=E /\left(1+\gamma_{1} E\right) \\
q_{j} \quad \text { catchability coefficient for gear-type } j, \\
\gamma, \gamma_{1} \quad \text { are control parameters (constrained to be positive), and } \\
l_{j, t} \quad \text { is the catch-rate index for gear-type } j \text { and year } t .
\end{gathered}
$$

The negative of the log-likelihood function (ignoring constant terms) is:

$$
-\ell \mathrm{n} L_{j}=\sum_{t(j)}\left(\ell \mathrm{n} \sigma_{j}+\frac{1}{2 \sigma_{j}^{2}}\left(\ell \mathrm{n}\left(q f\left(\tilde{C}_{t, j} / I_{j, t}\right)\right)-\ell \mathrm{n}\left(F_{t, j}\right)\right)^{2}\right)
$$

where $\sigma_{j}$ is the residual standard deviation (assumed to be 0.15 based on preliminary analyses) and the summation over $t$ is taken over all years for which catch rates are available for gear-type $j$.

\section{Length-frequency data}

The contribution of the length-frequency data (by gear-type) to the negative of the logarithm of the likelihood function is based on the assumption that the observed proportion of the catch by gear-type $j$ in length-class $L$ is multinomially distributed about the model prediction:

$$
-\ell \mathrm{n} L=-O_{j}^{\mathrm{len}} \sum_{g} \sum_{t} \frac{N_{g, t, j}^{\mathrm{len}}}{\bar{N}_{g, j}^{\mathrm{len}}} \sum_{L} \rho_{g, t, L, j} \ln \left(\hat{\rho}_{g, t, L, j} / \rho_{g, t, L, j}\right)
$$

where $\rho_{g, t, L, j}$ is the observed fraction of the catch of animals of sex $g$ during year $t$ by gear-type $j$ that lies in lengthclass $L$,

$N_{g, t, j}^{l e n}$ is the number of animals of sex $g$ caught by gear-type $j$ measured during year $t$,

$\bar{N}_{g, j}^{l e n} \quad$ is mean of $N_{g, t, j}^{l e n}$,

$O_{j}^{\text {len }} \quad$ is the weight assigned to the length-frequency data for gear-type $j$ (the average annual effective sample size; assumed to be 50 per sex for Bass Strait and 25 per sex for South Australia), and

$\hat{\rho}_{g, t, L, j}$ is the model-estimate of the fraction of the catch of animals of sex $g$ during year $t$ by gear-type $j$ that lies in length-class $L$ :

$$
\hat{\rho}_{g, t, L, j}=F_{t, j} A_{L} S_{g, j, L} \sum_{a} \Phi(g, a+1 / 2, L)\left(N_{g, t, a} e^{-M_{a} / 2}-\sum_{i=1}^{j-1} C_{g, t, a, i}\right) / \sum_{a^{\prime}} C_{g, t, a^{\prime}, j}
$$

\section{Age-composition data}

The contribution of the age-composition data (by gear-type) to the negative of the logarithm of the likelihood function is identical to Equation B.4, except that the observed and model-predicted fractions by age rather than by length are included in Equation B.4. The effective sample size for the age-composition data is assumed to be 25 per 
sex. The age-composition data are a small subset of the length-frequency data. Therefore, the impact of the doublecounting of the fish that were aged by including both the age- and length-frequency in the assessment simultaneously should not be marked.

\section{Tagging data}

The information for each release includes year-of-release, age-at-release (calculated from the growth curve and the length-at-release) and tag-type. The information for each recapture includes year- and age-at-recapture. The latter is calculated by adding the time-at-liberty to the age-at-release. Any releases for which complete information is not available are discarded (irrespective of whether they were recaptured or not). Ignoring constants, the contribution of the tagging data to the negative of the log-likelihood function is (Hilborn, 1990; Xiao, 1996):

$$
-\ell \mathrm{nL}=\sum_{t} \sum_{g}\left(\hat{R}_{g, t}-R_{g, t} \ell \mathrm{n} \hat{R}_{g, t}\right)
$$

where $R_{g, t}$ is the actual number of recaptures of animals of sex $g$ during year $t$, and

$\widehat{R}_{g, t}$ is the expected number of recaptures of animals of sex $g$ during year $t$.

The equation that governs the dynamics of tags is defined analogously to that which governs the dynamics of the population itself, except that 'births' to the tagged population occur when a tag is released, and account needs to be taken of tag shedding and 'early' recaptures ${ }^{5}$ :

$$
T_{t+1, a+1}^{z}=\left(T_{t, a}^{z} e^{-\left(M_{t, a}+\lambda^{2}\right)}+\left(I_{t, a}^{z}-\frac{1}{\theta_{t}^{z}} E_{t, a}^{z}\right) e^{-\left(M_{t, a}+\lambda^{2}\right) / 2}\right) \prod_{j}\left(1-F_{t, j} S_{g, j, a}\right)
$$

where $T_{t, a}^{z}$ is the number of fish of age $a$ with tag-type $z$ at the start of year $t$,

$I_{t, a}^{z}$ is the number of fish of age $a$ which were released with tag-type $z$ during year $t$,

$E_{t, a}^{z}$ is the number of fish of age $a$ that were recaptured with tag-type $z$ 'early' during year $t$,

$\theta_{t}^{z}$ is the tag recapture reporting rate (defined as the product of a year- and tag-type-specific factor),

$S_{g, j, a}$ is the selectivity of gear-type $j$ on fish of sex $g$ and age $a$ :

$$
S_{g, j, a}=\sum_{L} A_{L} S_{g, j, L} \Phi(g, a+1 / 2, L)
$$

$\lambda^{z}$ is the instantaneous (long-term) rate of tag shedding for tag-type $z$.

The tagging data included in the assessment are restricted to tag-types for which estimates of tag shedding are available. The expected number of fish of sex $g$ recaptured during year $t$ is given by:

$$
\hat{R}_{g, t}=\sum_{z} \theta_{t}^{z} \sum_{a}\left(1-\prod_{j}\left(1-F_{t, j} S_{g, j, a}\right)\right)\left(T_{t, a}^{z} e^{-\left(M_{t, a}+\lambda^{z}\right) / 2}+l_{t, a}^{z}-\frac{1}{\theta_{t}^{z}} E_{t, a}^{z}\right)
$$

\footnotetext{
5 An 'early recapture' is defined as a recapture that occurs before it is reasonable to assume that the tagged animal has been at
} liberty sufficiently long for it to have 'fully mixed' into the population. 